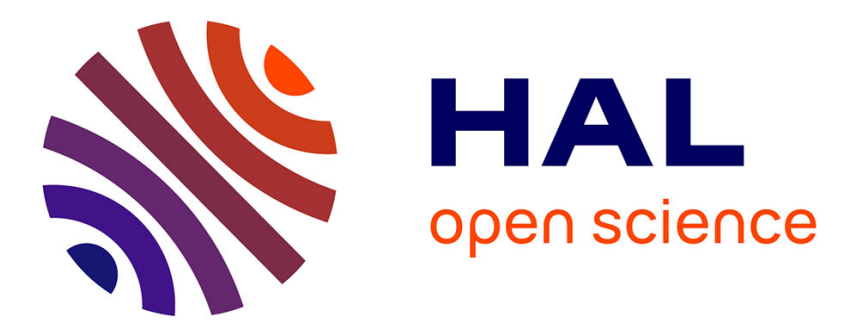

\title{
Isolated tricuspid valve surgery: impact of aetiology and clinical presentation on outcomes
}

Julien Dreyfus, Michele Flagiello, Baptiste Bazire, Florian Eggenspieler, Florence Viau, Elisabeth Riant, Yannick Mbaki, Yohann Bohbot, Damien Eyharts, Thomas Sénage, et al.

\section{To cite this version:}

Julien Dreyfus, Michele Flagiello, Baptiste Bazire, Florian Eggenspieler, Florence Viau, et al.. Isolated tricuspid valve surgery: impact of aetiology and clinical presentation on outcomes. European Heart Journal, 2020, 41 (45), pp.4304-4317. 10.1093/eurheartj/ehaa643 . hal-02959077

\section{HAL Id: hal-02959077 https://hal.science/hal-02959077}

Submitted on 19 Nov 2020

HAL is a multi-disciplinary open access archive for the deposit and dissemination of scientific research documents, whether they are published or not. The documents may come from teaching and research institutions in France or abroad, or from public or private research centers.
L'archive ouverte pluridisciplinaire HAL, est destinée au dépôt et à la diffusion de documents scientifiques de niveau recherche, publiés ou non, émanant des établissements d'enseignement et de recherche français ou étrangers, des laboratoires publics ou privés. 


\section{Isolated Tricuspid Valve Surgery - Impact of Etiology and Clinical Presentation on}

\section{Outcomes}

Julien Dreyfus, $\mathrm{MD}^{1}$; Michele Flagiello, $\mathrm{MD}^{2}$; Baptiste Bazire, $\mathrm{MD}^{3}$; Florian Eggenspieler, $\mathrm{MD}^{4}$; Florence Viau, $\mathrm{MD}^{5}$; Elisabeth Riant, $\mathrm{MD}^{6}$; Yannick Mbaki, $\mathrm{MD}^{7}$; Yohann Bohbot, $\mathrm{MD}^{8,9}$; Damien Eyharts, $\mathrm{MD}^{10}$; Thomas Senage, $\mathrm{MD}^{11}$; Henri Dubrulle, $\mathrm{MD}^{12}$; Martin Nicol, $\mathrm{MD}^{1}$; Fabien Doguet, MD ${ }^{13,14}$; Virginia Nguyen, $\mathrm{MD}, \mathrm{PhD}^{1}$; Augustin Coisne, $\mathrm{MD}, \mathrm{PhD}^{12,15}$; Thierry Le Tourneau, $\mathrm{MD}$, $\mathrm{PhD}^{16}$; Yoan Lavie-Badie, $\mathrm{MD}^{10}$; Christophe Tribouilloy, $\mathrm{MD}, \mathrm{PhD}^{8,9}$; Erwan Donal, $\mathrm{MD}, \mathrm{PhD}^{7}$; Jacques Tomasi, MD ${ }^{17}$; Gilbert Habib, MD ${ }^{5,18}$; Christine Selton-Suty, MD ${ }^{4}$, Richard Raffoul, $\mathrm{MD}^{19}$; Bernard Iung, MD²0; Jean-François Obadia, $\mathrm{MD}^{2}$; David Messika-Zeitoun, MD, PhD ${ }^{21}$

1: Cardiology Department, Centre Cardiologique du Nord, Saint-Denis, France.

2: Department of Cardiovascular Surgery and Transplantation, Louis Pradel Cardiovascular Hospital, Claude Bernard University, Bron, France.

3: Department of Cardiology, Bichat Claude Bernard Hospital, Paris, France.

4: Department of Cardiology, University Hospital of Nancy-Brabois, F-54000 Nancy, France.

5: APHM, La Timone Hospital, Cardiology Department, Marseille France.

6: Cardiology Department, Expert Valve Center, Henri Mondor Hospital, Créteil, France.

7: Cardiology Department, CHU de RENNES, LTSI UMR1099, INSERM, Université de Rennes1, Rennes, France.

8: Department of Cardiology, Amiens University Hospital, Amiens, France.

9: UR UPJV 7517, Jules Verne University of Picardie, Amiens, France.

10: Department of Cardiology, Rangueil University Hospital, F-31000 Toulouse, France. 
11. Department of cardiac surgery, INSERM 1246, Université de Nantes, CHU de Nantes.

12. CHU Lille, Department of Clinical Physiology and Echocardiography - Heart Valve Clinic, Lille, France.

13: Service de chirurgie cardiovasculaire et thoracique, CHU Charles Nicolle, Rouen, France.

14: Normandie Univ, Unirouen, INSERM U1096, 76000 Rouen, France.

15. Univ. Lille, Inserm, CHU Lille, Institut Pasteur de Lille, U1011- EGID, F-59000 Lille, France

16: Université de Nantes, CHU de Nantes, CNRS, INSERM, l'institut du thorax, F-44000 Nantes, France

17: Department of Cardiac Surgery, CHU de RENNES, Université de Rennes-1, Rennes, France.

18. Aix Marseille Univ, IRD, APHM, MEPHI, IHU-Méditerranée Infection, Marseille, France

19: Department of Cardiac Surgery, AP-HP, Bichat Hospital, Paris, France

20: AP-HP, Cardiology Department, DHU Fire, Bichat Hospital, Université de Paris, Paris, France

21: University of Ottawa Heart Institute, Ottawa, Canada

Short Title: Isolated tricuspid valve surgery

Words Count: 4521 (Introduction to conclusion)

\section{Addresses for correspondence:}

- Julien Dreyfus, Centre Cardiologique du Nord, Saint-Denis, France. Tel: +33149334803, Fax:

+33149334143, E-mail: dreyfusjulien@yahoo.fr 
- David Messika-Zeitoun, Department of Cardiology, University of Ottawa Heart Institute,

Ottawa, Canada. E-mail: DMessika-zeitoun@ottawaheart.ca 


\begin{abstract}
Aims. To identify determinants of in-hospital and mid-term outcomes after isolated tricuspid valve surgery (ITVS) and more specifically the impact of tricuspid regurgitation (TR) mechanism and clinical presentation.
\end{abstract}

Methods and Results. Among 5661 consecutive adult patients who underwent a tricuspid valve surgery at 12 French tertiary centers in 2007-2017 collected from a mandatory administrative database, we identified 466 patients ( $8 \%$ of all tricuspid surgeries) who underwent an ITVS. Most patients presented with advanced disease (47\% in NYHA III/IV, 57\% with right-sided heart failure (HF) signs). TR was functional in $49 \%$ (22\% with prior left-sided heart valve surgery and $27 \%$ isolated) and organic in 51\% (infective endocarditis in $31 \%$ and other causes in $20 \%$ ). In-hospital mortality and major complications rates were $10 \%$ and $31 \%$ respectively. Rates of survival and survival free of heart failure (HF) readmission were $75 \%$ and $62 \%$ at 5 years. Patients with functional TR incurred a worse in-hospital mortality than those with organic TR (14\% vs. $6 \%$, $\mathrm{P}=0.004$ ) but presentation was more severe. Independent determinants of outcomes were NYHA class III/IV $(\mathrm{OR}=2.7[1.2-6.1], \quad \mathrm{P}=0.01), \quad$ moderate/severe right ventricular dysfunction $(\mathrm{OR}=2.6[1.2-5.8], \mathrm{P}=0.02)$, lower prothrombin time $(\mathrm{OR}=0.98[0.96-0.99], \mathrm{P}=0.008)$ and with borderline statistical significance, right-sided HF signs $(\mathrm{OR}=2.4[0.9-6.5], \mathrm{P}=0.06)$ while $\mathrm{TR}$ mechanism was not $(\mathrm{OR}=0.7[0.3-1.8], \mathrm{P}=0.88)$.

Conclusion: ITVS was associated with high mortality and morbidity, both in-hospital and during follow-up, predicted by the severity of the presentation but not by TR mechanism. Our results suggest that TV intervention should be performed earlier in the course of the disease.

Keywords: tricuspid regurgitation, surgery, outcome 


\section{INTRODUCTION}

Tricuspid regurgitation (TR) is a frequent condition that has been overlooked compared to left sided valve diseases. Epidemiological studies suggest that moderate or severe TR affects over 1.6 million individuals in the US. $(1,2)$ Multiple studies, in various settings such as heart failure with reduced left ventricular ejection fraction (LVEF), tricuspid flail or isolated functional TR, have shown that presence and severity of TR are associated with an increased risk of mortality and of cardiovascular (CV) events.(3-8) In a recent meta-analysis, moderate/severe TR was associated with more than a two-fold increased cardiac mortality independently of pulmonary pressures, LVEF, and right ventricular (RV) dysfunction.(9) Despite its high prevalence, TR is often left untreated and the number of tricuspid valve surgeries, mostly performed at the time of mitral valve surgery, remains remarkably low.(10)

Isolated tricuspid valve surgery (ITVS) is reputed to be a high-risk surgery with a $10 \%$ inhospital mortality rate that had remained constant across studies and time despite improvement in surgical techniques and post-operative management.(10-12) However, most studies relied on small single-center studies or on administrative databases with limited clinical, biological and echocardiographic information and limited follow-up. Thus, determinants of outcome after ITVS have remained so far elusive. In a previous study, using the French Programme de Médicalisation des Systèmes d'Information (PMSI), a mandatory administrative database, congestive heart failure at presentation was associated with mortality and major complications rates.(12) However, granularity was limited and we were not able to account for the severity of the clinical presentation and echocardiographic features. In addition, TR mechanism may be either functional or organic and encompass multiple etiologies. Consequently, patients referred for ITVS represent a 
heterogeneous population. Impact of TR etiology on outcome remained unclear and data are very limited.

In the present study, relying on in depth characterization of patients' medical history, functional status, laboratory and echocardiography results, we aimed to evaluate the determinants of in-hospital and mid-term outcomes after ITVS according to TR mechanism and etiology and more specifically the impact of the severity of the clinical presentation.

\section{METHODS}

\section{Study Design}

Using the local Programme de Médicalisation des Systèmes d'Information (PMSI) database (13), we collected all consecutive cases of tricuspid valve (TV) surgery performed in adults patients at 12 tertiary French centers between January 1, 2007 and December 31, 2017 (Supplementary Figure 1). Tricuspid valve interventions were identified using Common Classification of Medical Procedures (CCAM) classification (DBKA004, DBMA008 or DBMA012).(14) All healthcare institutions in France are mandated to transfer information regarding their activity into the PMSI database and the PMSI database is therefore considered exhaustive. Among all tricuspid valve surgery cases performed in these centers, we excluded congenital tricuspid regurgitations and patients who underwent a combined TV surgery, meaning a TV surgery concomitant with other cardiac surgery such as mitral valve surgery, coronary artery bypass graft or atrial septal defect closure. Finally, we excluded all redo TV surgery either on native or prosthetic valves and our study population consisted of all patients who underwent an isolated non-congenital tricuspid valve surgery performed on native valve. Clinical presentation, laboratory results, echocardiography and 
immediate and mid-term outcome were retrospectively collected locally at each center. The study was approved by each local institutional review board.

\section{Patients' characteristics}

Information regarding clinical presentation, past medical history and laboratory results were retrospectively collected from patients' charts. Glomerular filtration rate was calculated using the Cockcroft-Gault formula according to sex. Surgical risk scores (logistic EuroSCORE, EuroSCORE II, and Society of Thoracic Surgeons (STS)) were calculated; mitral valve repair intervention was used for the STS as there is no dedicated score for isolated tricuspid valve surgery. $(15,16)$ The Charlson index was used to assess for patients' comorbidities.

All echocardiographic reports before intervention were reviewed and when needed measurements were retrospectively performed on digitally stored images. TR etiology was first classified as functional (no intrinsic tricuspid disease) or organic (due to abnormalities of the tricuspid leaflets or chordae). Functional TR were then subdivided into functional TR after leftsided valve surgery or isolated functional TR, and organic into endocarditis and other etiologies including carcinoid diseases or traumatic. Left-ventricular (LV) ejection fraction was measured visually or using the biplane method of disks (modified Simpson's rule). Right ventricular (RV) size was visually assessed as normal, mildly, moderately or severely enlarged. The RV basal diameter and the tricuspid annulus diameter (TA) were measured in diastole in the apical fourchamber view.(17) RV function was semi-quantitatively assessed using an integrative approach based on visual assessment, tricuspid annulus plane systolic excursion (TAPSE) and Doppler tissue imaging peak systolic annular velocity $S^{\prime}$ as recommended.(18, 19) Pulmonary artery systolic pressure was measured using the peak systolic trans-tricuspid pressure gradient and estimated right 
atrial pressure according to the diameter of the inferior vena cava and its variation with respiration, applying the Bernoulli equation.

\section{Outcome}

In-hospital mortality was defined as death occurring between the intervention and hospital discharge during the same hospital stay. Major post-operative complications were defined as death, shock, tamponade, acute renal failure requiring dialysis or prolonged ( $>72$ hours) mechanical ventilation. Lengths of stay (total and intensive care unit) were calculated as the time duration between the admission and hospital discharge. During follow-up, all-cause death and cardiovascular $(\mathrm{CV})$ readmissions, defined as due to congestive heart failure (CHF), atrial fibrillation (AF), infective endocarditis, stroke, acute coronary syndrome, re-intervention (tamponade, sternum infection) or pacemaker related were also collected based on hospital chart reviews and telephone interviews with patients or family members.

\section{Statistics}

Variables were expressed as mean \pm standard-deviation or median [percentile 25 and 75] for continuous variables and number of patients (percentage) for categorical variables. Trends in number and type of tricuspid valve surgery were estimated by the Mann-Kendall trend test. Comparisons between groups of TR mechanism / etiologies were performed using ANOVA, Chisquare, Student's t-test or nonparametric Wilcoxon test as appropriate. Complication rates were expressed as percentage and $95 \%$ confidence intervals. Logistic regressions in univariate and multivariate analysis (including variables with $\mathrm{p}<0.10$ in univariate analysis) were used to assess the determinants of in-hospital death and major post-operative complications. Variables 


\section{Dreyfus et. al}

Isolated tricuspid valve surgery

independently associated with mortality in each category (clinical, laboratory and echocardiographic) were entered into the final model. Multiple comparisons for continuous variables were tested with the Bonferroni correction. Odd-ratios (OR) along with $95 \%$ confidence intervals were reported. We assessed the risks of death and cardiovascular readmission overall and according to TR mechanism / etiology using Kaplan Meier estimates and Cox proportional hazard models. Data were analyzed using JMP version 9.0 (SAS Institute) or XLSTAT (Microsoft, Redmond, Washington). All tests were two-sided and a $\mathrm{p}$ value $<0.05$ was considered statistically significant.

\section{RESULTS}

\section{Trends in tricuspid valve surgery}

A total of 5,661 adult patients underwent a TV surgery (Supplementary Figure 2) at the 12 participating tertiary French centers between January 1, 2007 and December 31, 2017. Among them, 466 patients $(8 \%)$ had a non-congenital isolated TV surgery on native valve (Figure 1). Trends in TV surgery are presented in Figure 2. Number of TV surgery increased from 280 in 2007 to 774 in 2017 ( $\mathrm{P}$ for trend $<0.0001$ ). The increase in number of TV surgery performed was mainly related to a marked increase in the number of combined TV surgery $(\mathrm{P}$ for trend $<0.0001)$ although isolated TV modestly but significantly increased during the study period ( $\mathrm{P}$ for trend $=0.0001$ ).

\section{Clinical presentation and etiologies of isolated tricuspid valve surgery}

Characteristics of the 466 patients with a non-congenital isolated TV surgery on native valve are presented in Table 1 . Overall mean age was $60 \pm 16$ years and 229 patients (49\%) were 


\section{Dreyfus et. al}

female. One hundred and eleven patients (24\%) had a previous left-sided heart surgery. Close to half of the patients were severely symptomatic (47\% in NYHA functional class III/IV) and 163 (35\%) were admitted for congestive heart failure within the year preceding the surgery. Right-sided heart failure signs were present in 264 patients (57\%) in whom 39 (8\%) had ascites. Chronic kidney disease was present in 154 patients (33\%) and chronic liver disease in 54 patients (12\%). Mean left-ventricular ejection fraction was $58 \pm 9 \%$. A moderate / severe RV dilatation was present in $54 \%$ of patients and a moderate / severe RV dysfunction in $17 \%$. Mean systolic pulmonary artery pressure was $40 \pm 11 \mathrm{mmHg}$ ( $\geq 50 \mathrm{mmHg}$ in $19 \%$ ). Median Charlson comorbidity index was high (3.0 [1-4]), and 324 patients (70\%) had a Charlson comorbidity index $\geq 2$.

TR mechanism was functional in 229 patients (49\%) and organic in 237 patients (51\%). Among patients with functional TR, 101 patients $(22 \%)$ had a prior left-sided heart valve surgery and $128(27 \%)$ patients had an isolated functional TR (Figure 1). Among the 237 patients with organic disease, TR was due to infective endocarditis in 142 patients (31\%) and to other causes in 95 patients (20\%). Patients with functional TR were older, more frequently female and presented more often with cardiovascular risk factors and comorbidities than those with organic TR. Importantly clinical presentation was also more severe. Patients with functional TR presented more advanced signs of heart failure signs, worse laboratory results and more often moderate/severe right ventricular enlargement and dysfunction than patients with organic TR. The Charslon index was twice as high in patients with functional TR than in patients with organic TR. As expected, TV infective endocarditis affected a younger mainly male population with infrequent cardiovascular risk-factors. Clinical and echocardiographic RV parameters also tended to be less severe than those of the three other groups. Comparisons of baseline characteristics between functional and organic TR as well as between TR etiologies are presented in Table 1. 


\section{In-hospital outcomes of isolated tricuspid valve surgery}

A tricuspid valve repair was performed in 193 patients (41\%) and a replacement in 273 patients (59\%) (Supplementary Figure 2). A tricuspid valve replacement was more often performed when the tricuspid valve surgery was performed isolated than concomitant with other cardiac interventions $(59 \%$ vs. $4 \%, \mathrm{P}<0.0001)$. In most cases of isolated tricuspid valve surgery, a bioprosthetic valve was used $(n=264,57 \%)$ while a mechanical valve was implanted in only 9 patients $(2 \%)$. Surgery was urgent in 102 patients $(22 \%)$. Overall, in-hospital mortality rate was $10 \%(n=48)$ and major post-operative complications rate was $31 \%(n=145)$ (Table 2 and Figure 3$).$ In the post-operative period, 87 patients $(19 \%)$ presented a cardiogenic shock, 36 patients (8\%) a tamponade, $123(26 \%)$ acute renal failure, of whom 49 (11\%) requiring dialysis, $40(9 \%)$ a prolonged mechanical ventilation and $84(18 \%)$ needed a definitive pacemaker. Median intensive care unit and total lengths of stay were 4 days [2-8] and 18 days [12-29] respectively. Residual TR was rare and $98 \%$ of patients alive at discharge presented with less than moderate TR.

Factors associated with in-hospital death in univariate analysis are presented in Table 3 . Inhospital mortality was associated with older age and more severe presentation based on clinical, laboratory and echocardiographic assessment such as history of CHF, severe symptoms (NYHA class III/IV), presence of ascites, cirrhosis, dose of loop diuretics, kidney impairment, comorbidity index and surgical risk scores as well as degree of RV dilatation and dysfunction. Functional TR was also associated with higher in-hospital mortality rate than organic etiology (14\% vs $6 \%$, $\mathrm{P}=0.004)$ while history of previous left-sided heart valve surgery was not $(\mathrm{P}=0.10)$. Mortality rates according to TR etiology were $16 \%$ for functional TR after left-sided valve surgery, $13 \%$ for isolated functional TR, 5\% for infective endocarditis and $8 \%$ for organic TR of other etiology 
$(\mathrm{P}=0.02)$ (Figure 3). In multivariate analysis, independent determinants of in-hospital death were NYHA class III/IV (OR=2.7 [1.2-6.1], P=0.01), moderate / severe right ventricular dysfunction $(\mathrm{OR}=2.6[1.2-5.8], \mathrm{P}=0.02)$, lower prothrombin time $(\mathrm{OR}=0.98[0.96-0.99], \mathrm{P}=0.008)$ and with borderline statistical significance presence of right congestive heart failure signs $(\mathrm{OR}=2.4[0.9$ 6.5], $\mathrm{P}=0.06)$ while mechanism was not $(\mathrm{OR}=0.7[0.3-1.8], \mathrm{P}=0.88)$. Systolic pulmonary artery pressure $\geq 50 \mathrm{mmHg}$ was also of borderline statistical significance ( $\mathrm{OR}=2.5[0.9-7.0], \mathrm{P}=0.08)$. Independent determinants of major in-hospital complications in multivariate analysis were similar, with moderate / severe right ventricular dysfunction $(\mathrm{OR}=2.2[1.2-4.1], \mathrm{P}=0.01)$, lower glomerular filtration rate $(\mathrm{OR}=0.98$ [0.96-0.99], $\mathrm{P}=0.006)$, lower prothrombin time $(\mathrm{OR}=0.98$ [0.97-0.99], $\mathrm{P}=0.02)$ and, with borderline statistical significance, NYHA class III/IV (OR=1.6 [0.95-1.1], $\mathrm{P}=0.07)$, atrial fibrillation $(\mathrm{OR}=1.7[0.9-3.1], \mathrm{P}=0.08)$ and moderate / severe $\mathrm{RV}$ dilatation $(\mathrm{OR}=1.6[0.95-2.6], \mathrm{P}=0.08)$. Excluding patients with permanent pacemaker at the time of the surgery did not change our results. Our results also remained similar after the exclusion of patients with infective endocarditis or if the prothrombin time was not included into the model.

\section{Mid-term outcomes of isolated tricuspid valve surgery}

Follow-up was $90 \%$ complete. During an overall mean follow-up duration of $3.1 \pm 2.7$ years (median 2.6 years [0.8-4.9], up to 11.8 years), there were 40 additional deaths (all-cause) and 138 patients were readmitted for $\mathrm{CV}$ reasons including 64 patients for CHF. Overall rates of survival, survival free of CV readmission and survival free of $\mathrm{HF}$ readmission were $86 \%, 73 \%$ and $79 \%$ at 1 year and $75 \%, 44 \%$ and $62 \%$ at 5 years respectively (Figure $4 \mathrm{~A}$ ). Event rates among the 371 patients alive at 30 days and with available follow-up were $98 \%, 83 \%$ and $90 \%$ at 1 year and $85 \%$, $50 \%$ and $70 \%$ at 5 years respectively (Figure 4B). Survival, survival free of CV readmission and 
survival free of HF readmission curves according to TR etiology are presented in Figure 5 and were significantly worse for functional than for organic TR (all $\mathrm{P}<0.01$ ). Mortality and cardiovascular events according to TR etiologies further subdivided into functional TR after left-sided valve surgery, isolated functional TR, organic TR due to infective endocarditis and organic TR due other etiologies were also significantly different (all $\mathrm{P}<0.05$ ) (supplementary figure 3 ). However, outcome of both functional groups was not different (all $\mathrm{P}>0.40$ ).

In multivariate analysis, independent determinants of all-cause mortality were NYHA class III/IV $(\mathrm{HR}=1.7$ [1.1-2.8], $\mathrm{P}=0.04)$, presence of right congestive heart failure signs $(\mathrm{OR}=1.8[1.01$ 3.3], $\mathrm{P}<0.05)$, lower prothrombin time $(\mathrm{OR}=0.98[0.97-0.99], \mathrm{P}=0.04)$ and with borderline statistical significance functional etiology $(\mathrm{OR}=0.6[0.3-1.1], \mathrm{P}=0.07)$, lower glomerular filtration rate $(\mathrm{OR}=0.99$ [0.98-1.01], $\mathrm{P}=0.09)$ and moderate / severe right ventricular dilatation $(\mathrm{OR}=1.6[0.9$ 2.7], $\mathrm{P}=0.08$ ). Similar determinants were observed for all-cause mortality or CV readmissions (NYHA class III/IV $(\mathrm{OR}=1.4$ [1.0-2.0], $\mathrm{P}=0.05)$, presence of right congestive heart failure signs $(\mathrm{OR}=1.8[1.2-2.6], \mathrm{P}=0.002)$, lower prothrombin time $(\mathrm{OR}=0.99$ [0.99-0.99], $\mathrm{P}=0.03)$ and moderate / severe right ventricular dilatation $(\mathrm{OR}=1.6[1.1-2.3], \mathrm{P}=0.006))$ and for all-cause mortality or HF readmissions (NYHA class III/IV ( $\mathrm{OR}=1.7$ [1.1-2.3], $\mathrm{P}=0.02)$, presence of right congestive heart failure signs $(\mathrm{OR}=1.9[1.2-3.1], \mathrm{P}=0.006)$ and moderate / severe right ventricular dilatation $(\mathrm{OR}=2.0[1.3-3.1], \mathrm{P}=0.002))$. Functional etiology was not an independent determinant of mortality or $(\mathrm{CV}$ or $\mathrm{HF})$ readmissions $(\mathrm{OR}=0.9[0.6-1.4], \mathrm{P}=0.67$ and $\mathrm{OR}=0.9[0.5-1.3], \mathrm{P}=0.37$ respectively).

\section{DISCUSSION}


In this retrospective series, we collected all cases of tricuspid valve surgery performed at 12 tertiary French centers between January 1, 2007 and December 31, 2017 and assessed the clinical, biological and echocardiographic presentation and immediate and mid-term outcomes of isolated tricuspid valve surgery. Main results of the present study can be summarized as follow. 1) Although total numbers had increased over time, tricuspid valve surgery remained seldom performed. 2) TV surgery was mainly concomitant with another surgical procedure and rarely isolated. 3) ITVS was performed in approximately half of cases for functional TR (after left-sided valve surgery in $46 \%$ and for isolated functional TR in 54\%) and in the other half for organic TR (due to infective endocarditis in 60\%). 4) Patients were often referred late in the course of the disease with severe symptoms, frequent impairment of liver and kidney functions and advanced RV consequences. 5) In-hospital mortality and CV events rates were high with long in-hospital lengths of stay. 6) Although in-hospital mortality and morbidity were significantly worse for functional TR than for organic TR, outcome was more related to the severity of the clinical presentation observed in this subgroup than to TR mechanism or etiology, which portended limited independent prognostic information. 7) Mid-term outcomes showed substantial rates of death and readmissions also predicted by the severity of the presentation.

Using the PMSI, a mandatory French administrative database, we were able to identify all TV surgeries performed at 12 tertiary French centers over the past 10 years. Based on our previous nationwide study, these 12 centers accounted for $40 \%$ of all TV surgery performed in France.(12) Number of tricuspid valve surgeries increased over time, from less to 300 in 2007 to close to 800 in 2017 but remained far from the number of aortic valve replacements $(>10,000 /$ year $)$ or mitral valve interventions (>6,000/year) currently performed in France.(20) The vast majority of TV 


\section{Dreyfus et. al}

Isolated tricuspid valve surgery

interventions consisted of a TV repair performed concomitant with another procedure, mostly with left-sided valve surgery. Both the American College of Cardiology / American Heart Association and the European Society of Cardiology guidelines recommend performance of a combined TV surgery during left-sided valve surgery in case of moderate-severe TR or TV annulus diameter > $40 \mathrm{~mm} .(21,22)$ Assuming the number of mitral valve surgeries has remained stable during the study period, the present study suggest a wider adoption of these recommendations but also suggest that a substantial number of patients with qualifying indication for combined TV interventions remains neglected.

Recent epidemiological studies have shown that TR prevalence was similar to that of aortic stenosis and mitral regurgitation.(2, 23) In the community, prevalence of significant - moderate or severe - TR was estimated to be as high as $0.55 \%$ and up to $3 \%$ after 75 years.(1) Despite its high prevalence and its strong association with poor outcomes, $(3-5,9,24,25) \mathrm{TR}$ is often left untreated. Intervention (surgery or transcatheter) is the only curative treatment for severe TR and medical therapy should be considered as only palliative. The magnitude of the gap between the estimated TR prevalence and the observed rates of interventions for TR (approximately 40/years ITVS in the present study, 100-120/year at the nationwide level) is thus striking. Management of isolated severe TR often relies on two contradictory beliefs: one that severe TR is a benign condition and the other that ITVS is a high-risk surgery. In clinical practice, patients are often initially not referred for an intervention arguing it is too early until they are deemed at too high risk and denied surgery due to a too advanced disease. The literature is fairly consistent showing that in-hospital mortality of ITVS is approximately $10 \%$ and has remained stable over time.(10,12) The present study confirms these findings with a similar $10 \%$ in-hospital mortality rate. In addition, we also showed that mid-term mortality and $\mathrm{CV}$ events rates were substantial. At 5 years, one quarter of patients are dead, more 
than half are either dead or admitted for CV reasons and one third dead or admitted for heart failure. Importantly, mortality rates are highly variable according to patients' characteristics. In contrast to previous studies including ours, we were able to obtain much more details regarding TR etiology and clinical presentation including laboratory and echocardiographic results and to evaluate the determinants of outcomes after ITVS. Most patients presented with advanced disease, severe CHF, kidney, liver or RV dilatation / dysfunction. It is worth noting that the Charlson index in the present study was more than twice as high as the Charlson index observed in patients referred for transcatheter aortic valve implantation in the early days.(20) Functional TR accounted for half of ITVS performed and was associated with mortality and rates twice as high as organic TR. However, the observed worse outcome in patients with functional TR was mainly due to a more severe clinical, biological and echocardiographic pre-operative presentation. Thus, NYHA class, presence of right congestive heart failure signs, prothrombin time or moderate / severe right ventricular dilatation or dysfunction were important determinants of outcomes whereas TR mechanism or etiology were not when adjusted on patients' characteristics including infective endocarditis as these patients presented milder TR consequences. Similarly, previous left-sided heart valve surgery and TV replacement (vs. repair) were marker of advanced disease but were not independent determinants of the outcome. It is worth noting that repair rates for IVTS were similar than in the US but use of mechanical valves was much lower (one-third of TV replacements in the US compared to only $3 \%$ in the present study).(10) Thus, in-hospital mortality of patients with ascites and RV dysfunction were $26 \%$ and $22 \%$ respectively. Importance of RV size and function and of their combination has also been recently highlighted in a large series of patients with functional TR.(26) Results of ITVS are even more striking considering that the population was relatively young and that TV surgery is relatively simple. Interestingly, there is no dedicated 


\section{Dreyfus et. al}

surgical risk scoring for ITVS and those for mitral valve surgery markedly underestimated the observed mortality rates. Altogether, our results suggest that the paradigm should be shifted: the high mortality and morbidity observed after ITVS is more related to patients' late referral with advanced symptoms, kidney and liver dysfunction and RV consequences than to the surgical intervention per se.

Strengths and limitations of the present study need to be discussed. First, we retrospectively collected TV surgery cases performed at 12 French centers. However, identification of cases at these centers was performed using the PMSI, a mandatory database considered exhaustive and we thus captured all cases done at these centers. In addition, based on our previous study we were able to estimate that our 12 centers accounted for $40 \%$ of all IVTS performed in France insuring generalizability of our findings. Second, in contrast to previously published studies using administrative databases, which lack granularity and with limited follow-up, we were able to provide in depth assessment of patients' presentation including labs and echocardiographic results. Such level of details, as well as our sample size, unique in the literature, enabled us to identify the mechanism of TR and determinants of in-hospital and mid-term outcomes. Third, echocardiographic evaluation relied on centers' evaluation and not on a centralized laboratory. Assessment of RV dilatation or dysfunction was based on an integrative approach performed by each center and we could not provide specific thresholds for RV dilatation or dysfunction that could have guided surgical indications. Nevertheless, as an internal validation, RV basal diameter was markedly different between patients classified as presenting a moderate/severe RV dilatation compared to those who did not $(54 \pm 8$ vs. $42 \pm 10 \mathrm{~mm}, \mathrm{p}<0.0001)$, and tricuspid annulus plane systolic excursion (TAPSE) and Doppler tissue imaging peak systolic annular velocity S' were markedly different between patients who presented with moderate/severe RV dysfunction 


\section{Dreyfus et. al}

compared to those who did not $(13 \pm 4$ vs. $21 \pm 6 \mathrm{~mm}$ and $7.6 \pm 1.5 \mathrm{vs} .12 .4 \pm 3.2 \mathrm{~cm} / \mathrm{s}$ respectively, both $\mathrm{P}<0.0001)$. Fourth, as a retrospective study, not all laboratory and echocardiographic parameters could be collected for all patients. However, main parameters of interest were available in the vast majority of our population. In addition, we did not collect information regarding right catheterization performance and results. It is probable that patients with high systolic pulmonary pressure would be those with the highest event rates and those who might benefit the less from the intervention. Systolic pulmonary artery pressure measured using echocardiography was of borderline statistical significance but was only available in 274 patients (59\%) and may be underestimated in patients with severe / laminar TR. Fifth, tricuspid annulus diameter was not predictive of outcome in the overall population as well as in the subgroup of patients with functional TR. These findings should be interpreted in light of the baseline characteristics of our population as most patients presented with significant tricuspid annulus enlargement while prognostic value of tricuspid annulus diameter has been shown in less selected patients.(26) Sixth, assessment of TR etiology and mechanism may be challenging in few patients in particular in the presence of permanent pacemaker. However, our results remained unchanged after exclusion of the 104 patients with pacemaker. Finally, we could only infer that the high mortality and morbidity observed in the present study is related to a late surgical referral and that an earlier surgery would have improved the outcome. However, the limited impact of TR etiology on in-hospital and midterm outcomes compared to the weight of the clinical presentation including laboratory and echocardiographic TR consequences strongly support this hypothesis. Future randomized controlled trials will evaluate the impact of TR correction on outcome and identify patients that will benefit the most of an intervention.

With regards to clinical implications, the present study highlights the need to prevent the 


\section{Dreyfus et. al}

Isolated tricuspid valve surgery

occurrence of late TR after left-sided surgery and the importance of timely referral for TV interventions. As mentioned above, although debated, a more aggressive approach on TV intervention at the time of the left-sided surgery should be advocated to prevent occurrence of late TR and the need for a repeat intervention seldom performed in real life. The high mortality and morbidity rates observed during ITVS for functional TR after left-sided valve surgery should be regarded as a strong incentive for the performance of concomitant TV surgery when indicated. On the other hand, timely referral for intervention of patients with severe TR is also critical. Current guidelines $(21,22)$ are quite vague with no class I recommendation for intervention but as for other valvular diseases, patients with severe TR should be referred earlier in the course of the disease avoiding performance of TV intervention in patients with advanced disease at a desperate stage. In this regard, evaluation of RV size and function, often challenging especially in the setting of severe TR, should be refined. It is worth noting that we have illuminated only part of the problem as many patients with severe TR are often conservatively managed and denied any intervention. Thus, mortality and morbidity related to TR is likely underestimated. In a near future, the development of transcatheter therapies may represent an alternative to surgery and will further push for an early intervention if proved to be safe and efficient. As for functional mitral regurgitation $(27,28)$, patients' selection will be critical and "early" intervention before the occurrence of irreversible consequences will be key. Impact of TR correction on outcome has been recently disputed. $(29,30)$ A later referral in surgical than transcatheter series may explain the contradictory results reported in the literature. Compared to our population, patients who underwent a transcatheter intervention were older (77 years), the vast majority presented with functional TR in atrial fibrillation (90\% and $83 \%$ respectively) with concomitant $3+/ 4+$ mitral regurgitation while pulmonary pressure was similar. Patients referred for surgery were of similar age, similarly symptomatic than our functional 
TR subset but presented with higher systolic pulmonary pressures.

\section{CONCLUSION}

In this large multicenter series, we collected all cases of tricuspid valve surgery performed at 12 tertiary French centers between January 1, 2007 and December 31, 2017 and assessed the clinical presentation and immediate and mid-term outcomes of isolated tricuspid valve surgery. Compared to aortic or mitral valve surgery, tricuspid surgery remained uncommon and mainly performed at the time of left-sided surgery. Isolated tricuspid valve surgery was rare, associated with high mortality and morbidity, both in-hospital and during follow-up, predicted by the severity of the clinical presentation while TR mechanism / etiology had limited impact. Our results suggest adopting a more aggressive approach for tricuspid valve intervention, either at the time of leftsided surgery to prevent the occurrence of late TR, or intervening earlier in the course of the disease for patients with severe isolated TR, whatever the mechanism, before the occurrence of advanced / irreversible consequences and intractable heart failure.

\section{ACKNOWLEDGEMENTS}

None

\section{FUNDING}

None

\section{Conflict of interest}

Bernard Iung received consultant fees from Edwards. 
Jean-François Obadia received consultant fees for Abbott, Carmat, Delacroix-Chevalier, Landanger, Medtronic, Sorin.

David Messika-Zeitoun received consultant fees from Edwards.

Other authors have no relationship to declare. 


\section{REFERENCES}

1. Topilsky Y, Maltais S, Medina Inojosa J, Oguz D, Michelena H, Maalouf J, Mahoney DW, Enriquez-Sarano M. Burden of Tricuspid Regurgitation in Patients Diagnosed in the Community Setting. JACC Cardiovasc Imaging 2019; 12(3):433-442.

2. Stuge O, Liddicoat J. Emerging opportunities for cardiac surgeons within structural heart disease. J Thorac Cardiovasc Surg 2006; 132(6):1258-1261.

3. Benfari G, Antoine C, Miller WL, Thapa P, Topilsky Y, Rossi A, Michelena HI, Pislaru S, Enriquez-Sarano M. Excess Mortality Associated With Functional Tricuspid Regurgitation Complicating Heart Failure With Reduced Ejection Fraction. Circulation 2019; 140(3):196-206.

4. Messika-Zeitoun D, Thomson H, Bellamy M, Scott C, Tribouilloy C, Dearani J, Tajik AJ, Schaff H, Enriquez-Sarano M. Medical and surgical outcome of tricuspid regurgitation caused by flail leaflets. J Thorac Cardiovasc Surg 2004; 128(2):296-302.

5. Topilsky Y, Inojosa JM, Benfari G, Vaturi O, Maltais S, Michelena H, Mankad S, EnriquezSarano M. Clinical presentation and outcome of tricuspid regurgitation in patients with systolic dysfunction. Eur Heart J 2018; 39(39):3584-3592.

6. Koelling TM, Aaronson KD, Cody RJ, Bach DS, Armstrong WF. Prognostic significance of mitral regurgitation and tricuspid regurgitation in patients with left ventricular systolic dysfunction. Am Heart J 2002; 144(3):524-529.

7. Nath J, Foster E, Heidenreich PA. Impact of tricuspid regurgitation on long-term survival. J Am Coll Cardiol 2004; 43(3):405-409.

8. Neuhold S, Huelsmann M, Pernicka E, Graf A, Bonderman D, Adlbrecht C, Binder T, Maurer G, Pacher R, Mascherbauer J. Impact of tricuspid regurgitation on survival in patients with chronic heart failure: unexpected findings of a long-term observational study. Eur Heart J 2013; 34(11):844-852.

9. Wang N, Fulcher J, Abeysuriya N, McGrady M, Wilcox I, Celermajer D, Lal S. Tricuspid regurgitation is associated with increased mortality independent of pulmonary pressures and right heart failure: a systematic review and meta-analysis. Eur Heart J 2019; 40(5):476-484.

10. Zack CJ, Fender EA, Chandrashekar P, Reddy YNV, Bennett CE, Stulak JM, Miller VM, Nishimura RA. National Trends and Outcomes in Isolated Tricuspid Valve Surgery. J Am Coll Cardiol 2017; 70(24):2953-2960.

11. De Meester P, Van De Bruaene A, Voigt JU, Herijgers P, Budts W. Outcome and determinants of prognosis in patients undergoing isolated tricuspid valve surgery: retrospective single center analysis. Int J Cardiol 2014; 175(2):333-339.

12. Dreyfus J, Ghalem N, Garbarz E, Cimadevilla C, Nataf P, Vahanian A, Caranhac G, Messika-Zeitoun D. Timing of Referral of Patients With Severe Isolated Tricuspid Valve Regurgitation to Surgeons (from a French Nationwide Database). Am J Cardiol 2018; 122(2):323326.

13. PMSI. Programme de médicalisation des systèmes d'informations (PMSI). http://wwwdreessantegouvfr/redressements-du-programme-de-medicalisation-des-systemes-dinformations-pmsi, 2012.

14. CCAM. Classification commune des actes médicaux(CCAM). http://wwwamelifr/accueilde-la-ccam/trouver-un-acte/indexphp 2012. 
15. Nashef SA, Roques F, Michel P, Gauducheau E, Lemeshow S, Salamon R. European system for cardiac operative risk evaluation (EuroSCORE). Eur J Cardiothorac Surg 1999; 16(1):9-13.

16. O'Brien SM, Shahian DM, Filardo G, Ferraris VA, Haan CK, Rich JB, Normand SL, DeLong ER, Shewan CM, Dokholyan RS, Peterson ED, Edwards FH, Anderson RP. The Society of Thoracic Surgeons 2008 cardiac surgery risk models: part 2--isolated valve surgery. Ann Thorac Surg 2009; 88(1 Suppl):S23-42.

17. Dreyfus J, Durand-Viel G, Raffoul R, Alkhoder S, Hvass U, Radu C, Al-Attar N, Ghodbhane W, Attias D, Nataf P, Vahanian A, Messika-Zeitoun D. Comparison of 2-Dimensional, 3-Dimensional, and Surgical Measurements of the Tricuspid Annulus Size: Clinical Implications. Circ Cardiovasc Imaging 2015; 8(7):e003241.

18. Zoghbi WA, Adams D, Bonow RO, Enriquez-Sarano M, Foster E, Grayburn PA, Hahn RT, Han Y, Hung J, Lang RM, Little SH, Shah DJ, Shernan S, Thavendiranathan P, Thomas JD, Weissman NJ. Recommendations for Noninvasive Evaluation of Native Valvular Regurgitation: A Report from the American Society of Echocardiography Developed in Collaboration with the Society for Cardiovascular Magnetic Resonance. J Am Soc Echocardiogr 2017; 30(4):303-371.

19. Zoghbi WA, Enriquez-Sarano M, Foster E, Grayburn PA, Kraft CD, Levine RA, Nihoyannopoulos P, Otto CM, Quinones MA, Rakowski H, Stewart WJ, Waggoner A, Weissman NJ. Recommendations for evaluation of the severity of native valvular regurgitation with twodimensional and Doppler echocardiography. J Am Soc Echocardiogr 2003; 16(7):777-802.

20. Nguyen V, Michel M, Eltchaninoff H, Gilard M, Dindorf C, Iung B, Mossialos E, Cribier A, Vahanian A, Chevreul K, Messika-Zeitoun D. Implementation of Transcatheter Aortic Valve Replacement in France. J Am Coll Cardiol 2018; 71(15):1614-1627.

21. Baumgartner H, Falk V, Bax JJ, De Bonis M, Hamm C, Holm PJ, Iung B, Lancellotti P, Lansac E, Munoz DR, Rosenhek R, Sjogren J, Tornos Mas P, Vahanian A, Walther T, Wendler O, Windecker S, Zamorano JL. 2017 ESC/EACTS Guidelines for the management of valvular heart disease: The Task Force for the Management of Valvular Heart Disease of the European Society of Cardiology (ESC) and the European Association for Cardio-Thoracic Surgery (EACTS). Eur Heart $J$ 2017; 38(36):2739-2791.

22. Nishimura RA, Otto CM, Bonow RO, Carabello BA, Erwin JP, 3rd, Fleisher LA, Jneid H, Mack MJ, McLeod CJ, O'Gara PT, Rigolin VH, Sundt TM, 3rd, Thompson A. 2017 AHA/ACC Focused Update of the 2014 AHA/ACC Guideline for the Management of Patients With Valvular Heart Disease: A Report of the American College of Cardiology/American Heart Association Task Force on Clinical Practice Guidelines. Circulation 2017; 135(25):e1159-e1195.

23. Nkomo VT, Gardin JM, Skelton TN, Gottdiener JS, Scott CG, Enriquez-Sarano M. Burden of valvular heart diseases: a population-based study. Lancet 2006; 368(9540):1005-1011.

24. Prihadi EA, van der Bijl P, Gursoy E, Abou R, Mara Vollema E, Hahn RT, Stone GW, Leon MB, Ajmone Marsan N, Delgado V, Bax JJ. Development of significant tricuspid regurgitation over time and prognostic implications: new insights into natural history. Eur Heart $J$ 2018; 39(39):3574-3581.

25. Topilsky Y, Nkomo VT, Vatury O, Michelena HI, Letourneau T, Suri RM, Pislaru S, Park S, Mahoney DW, Biner S, Enriquez-Sarano M. Clinical outcome of isolated tricuspid regurgitation. JACC Cardiovasc Imaging 2014; 7(12):1185-1194.

26. Dietz MF, Prihadi EA, van der Bijl P, Goedemans L, Mertens BJA, Gursoy E, van Genderen OS, Ajmone Marsan N, Delgado V, Bax JJ. Prognostic Implications of Right Ventricular 
Remodeling and Function in Patients With Significant Secondary Tricuspid Regurgitation. Circulation 2019; 140(10):836-845.

27. Obadia JF, Messika-Zeitoun D, Leurent G, Iung B, Bonnet G, Piriou N, Lefevre T, Piot C, Rouleau F, Carrie D, Nejjari M, Ohlmann P, Leclercq F, Saint Etienne C, Teiger E, Leroux L, Karam N, Michel N, Gilard M, Donal E, Trochu JN, Cormier B, Armoiry X, Boutitie F, MaucortBoulch D, Barnel C, Samson G, Guerin P, Vahanian A, Mewton N. Percutaneous Repair or Medical Treatment for Secondary Mitral Regurgitation. N Engl J Med 2018; 379(24):2297-2306. 28. Stone GW, Lindenfeld J, Abraham WT, Kar S, Lim DS, Mishell JM, Whisenant B, Grayburn PA, Rinaldi M, Kapadia SR, Rajagopal V, Sarembock IJ, Brieke A, Marx SO, Cohen DJ, Weissman NJ, Mack MJ. Transcatheter Mitral-Valve Repair in Patients with Heart Failure. $N$ Engl J Med 2018; 379(24):2307-2318.

29. Axtell AL, Bhambhani V, Moonsamy P, Healy EW, Picard MH, Sundt TM, 3rd, Wasfy JH. Surgery Does Not Improve Survival in Patients With Isolated Severe Tricuspid Regurgitation. $J$ Am Coll Cardiol 2019; 74(6):715-725.

30. Taramasso M, Benfari G, van der Bijl P, Alessandrini H, Attinger-Toller A, Biasco L, Lurz P, Braun D, Brochet E, Connelly KA, de Bruijn S, Denti P, Deuschl F, Estevez-Loureiro R, Fam N, Frerker C, Gavazzoni M, Hausleiter JR, Ho E, Juliard JM, Kaple R, Besler C, Kodali S, Kreidel F, Kuck KH, Latib A, Lauten A, Monivas V, Mehr M, Muntane-Carol G, Nazif T, Nickening G, Pedrazzini G, Philippon F, Pozzoli A, Praz F, Puri R, Rodes-Cabau J, Scha Fer U, Schofer J, Sievert H, Tang GHL, Thiele H, Topilsky Y, Rommel KP, Delgado V, Vahanian A, Von Bardeleben RS, Webb JG, Weber M, Windecker S, Winkel M, Zuber M, Leon MB, Hahn RT, Bax JJ, EnriquezSarano M, Maisano F. Transcatheter versus medical treatment of symptomatic severe tricuspid regurgitation. J Am Coll Cardiol 2019; 74(24):2998-3008. 


\section{Figure 1. Flow chart of study population.}

A total of 5,661 adult patients underwent a tricuspid valve surgery at 12 tertiary French centers between January 1, 2007 and December 31, 2017. Among them, 466 had an isolated non-congenital surgery, 229 for functional tricuspid regurgitation (TR) and 237 for organic TR. Functional tricuspid regurgitations were then subdivided into functional TR after left-sided surgery or isolated functional TR, and organic into endocarditis etiology and other etiologies including carcinoid diseases or traumatic.

Figure 2. Trends in tricuspid valve surgery between January 1, 2007 and December 31, 2017 in the 12 tertiary French centers.

(A) All tricuspid valve (TV) surgery, combined TV surgery and isolated TV surgery on native valve. (B) TV repair and TV replacement - bioprosthetic and mechanical valves.

Figure 3. In-hospital mortality and major post-operative complications rates overall and according to the etiology of the tricuspid regurgitation.

Figure 4. Overall events rates (A) and with a landmark analysis for patients alive at 30 days (B).

The figure displays Kaplan-Meier curves of all-cause mortality (in grey), all-cause mortality or readmission for cardiovascular reasons (in yellow) and all-cause mortality or readmission for heart failure (in brown).

Figure 5. Events rate according to the etiology (functional or organic) of the tricuspid 


\section{regurgitation}

The figure displays Kaplan-Meier curves of (A) Survival (from all-cause death), (B) Survival (from all-cause death) free of cardiovascular readmission and (C) Survival (from all-cause death) free of heart failure readmission for functional (in red) and organic (in purple) etiology. 
TABLE 1: Baseline characteristics of the population overall and according to the etiology of the tricuspid regurgitation.

\begin{tabular}{|c|c|c|c|c|c|c|c|c|c|}
\hline Characteristics & $\begin{array}{l}\text { Overall } \\
(\mathrm{N}=466)\end{array}$ & $\begin{array}{l}\text { Functional } \\
(\mathbf{N}=\mathbf{2 2 9})\end{array}$ & $\begin{array}{l}\text { Organic } \\
(\mathrm{N}=237)\end{array}$ & P-value & $\begin{array}{c}\text { Functional - } \\
\text { Prior left-sided } \\
\text { heart valve } \\
\text { surgery } \\
(\mathbf{N}=101)\end{array}$ & $\begin{array}{c}\text { Functional - } \\
\text { Isolated } \\
(\mathbf{N}=128)\end{array}$ & $\begin{array}{c}\text { Organic - } \\
\text { Infective } \\
\text { endocarditis } \\
(\mathbf{N}=142)\end{array}$ & $\begin{array}{c}\text { Organic - } \\
\text { Other } \\
(\mathbf{N}=95)\end{array}$ & P-value \\
\hline Age, years & $60 \pm 16$ & $66 \pm 11$ & $53 \pm 18$ & $<0.0001$ & $66 \pm 11$ & $67 \pm 12$ & $49 \pm 17$ & $61 \pm 15$ & $<0.0001$ \\
\hline Female gender & $229(49)$ & $137(60)$ & $92(39)$ & $<0.0001$ & $64(63)$ & $73(57)$ & $43(30)$ & $49(52)$ & $<0.0001$ \\
\hline Body mass index, $\mathrm{kg} / \mathrm{m}^{2}$ & $25 \pm 5$ & $27 \pm 6$ & $24 \pm 5$ & $<0.0001$ & $26 \pm 5$ & $27 \pm 6$ & $24 \pm 5$ & $25 \pm 5$ & $<0.0001$ \\
\hline Hypertension & $190(41)$ & $120(52)$ & $70(30)$ & $<0.0001$ & $47(47)$ & $73(57)$ & $31(22)$ & $39(41)$ & $<0.0001$ \\
\hline Diabetes mellitus & $62(13)$ & $40(18)$ & $22(9)$ & 0.009 & $19(19)$ & $21(16)$ & $13(9)$ & $9(10)$ & 0.07 \\
\hline Chronic lung disease & $51(11)$ & $30(13)$ & $21(9)$ & 0.14 & $14(14)$ & $16(13)$ & $13(9)$ & $8(8)$ & 0.52 \\
\hline Peripheral vascular disease & $16(3)$ & $5(2)$ & $11(5)$ & 0.15 & $1(1)$ & $4(3)$ & $8(6)$ & $3(3)$ & 0.27 \\
\hline Prior stroke & $41(9)$ & $24(11)$ & $17(7)$ & 0.21 & $15(15)$ & $9(7)$ & $9(6)$ & $8(8)$ & 0.10 \\
\hline Prior left-sided heart valve surgery & $111(24)$ & $101(44)$ & $10(4)$ & $<0.0001$ & $101(100)$ & $0(0)$ & $1(1)$ & $9(10)$ & $<0.0001$ \\
\hline Coronary artery disease & $59(13)$ & $35(15)$ & $24(10)$ & 0.09 & $20(20)$ & $15(12)$ & $12(9)$ & $12(13)$ & 0.07 \\
\hline Chronic kidney disease & $154(33)$ & $100(44)$ & $54(23)$ & $<0.0001$ & $52(51)$ & $48(38)$ & $28(20)$ & $26(27)$ & $<0.0001$ \\
\hline Chronic liver disease & $54(12)$ & $31(14)$ & $23(10)$ & 0.20 & $16(16)$ & $15(12)$ & $10(7)$ & $13(14)$ & 0.17 \\
\hline Liver cirrhosis & $11(2)$ & $7(3)$ & $4(2)$ & 0.33 & $5(5)$ & $2(2)$ & $0(0)$ & $4(4)$ & 0.04 \\
\hline Permanent pacemaker & $104(22)$ & $54(24)$ & $50(21)$ & 0.52 & $26(26)$ & $28(22)$ & $29(20)$ & $21(22)$ & 0.80 \\
\hline $\begin{array}{l}\text { Hospitalization for congestive heart } \\
\text { failure }(<1 \text { year) }\end{array}$ & $163(35)$ & $121(53)$ & $42(18)$ & $<0.0001$ & $57(56)$ & $64(50)$ & $16(11)$ & $26(27)$ & $<0.0001$ \\
\hline Systolic blood pressure, $\mathrm{mmHg}$ & $125 \pm 19$ & $126 \pm 19$ & $124 \pm 20$ & 0.36 & $123 \pm 19$ & $127 \pm 19$ & $122 \pm 19$ & $127 \pm 20$ & 0.10 \\
\hline Diastolic blood pressure, $\mathrm{mmHg}$ & $73 \pm 13$ & $72 \pm 13$ & $73 \pm 14$ & 0.35 & $70 \pm 13$ & $74 \pm 13$ & $73 \pm 14$ & $74 \pm 14$ & 0.16 \\
\hline NYHA functional class III-IV & $217(47)$ & $136(59)$ & $81(34)$ & $<0.0001$ & $62(61)$ & $74(58)$ & $41(29)$ & $40(42)$ & $<0.0001$ \\
\hline Right-sided heart failure signs & $264(57)$ & $166(73)$ & $98(41)$ & $<0.0001$ & $80(79)$ & $86(67)$ & $48(34)$ & $50(53)$ & $<0.0001$ \\
\hline Ascites & $39(8)$ & $29(13)$ & $10(4)$ & 0.001 & $15(15)$ & $14(11)$ & $1(1)$ & $9(10)$ & 0.0005 \\
\hline Loop diuretics & $301 / 451(67)$ & $194 / 222(87)$ & $107 / 229(47)$ & $<0.0001$ & $96(95)$ & $98 / 121(81)$ & $49 / 136(36)$ & $58 / 93(62)$ & $<0.0001$ \\
\hline Daily dose of loop diuretics, mg & $40[0-80]$ & $60[40-120]$ & $0[0-40]$ & 0.0006 & $80[40-125]$ & $40[20-120]$ & $0[0-40]$ & $40[0-80]$ & 0.003 \\
\hline Atrial fibrillation & $180(39)$ & $142(62)$ & $39(17)$ & $<0.0001$ & $66(65)$ & $76(59)$ & $17(12)$ & $22(23)$ & $<0.0001$ \\
\hline Hemoglobin, g/dl & $12.3 \pm 2.3$ & $12.5 \pm 2.0$ & $12.1 \pm 2.5$ & 0.06 & $12.1 \pm 1.9$ & $12.8 \pm 2.0$ & $11.2 \pm 2.5$ & $13.4 \pm 2.0$ & $<0.0001$ \\
\hline Glomerular filtration rate, $\mathrm{ml} / \mathrm{min}$ & $72 \pm 39$ & $61 \pm 29$ & $82 \pm 44$ & $<0.0001$ & $60 \pm 28$ & $60 \pm 30$ & $93 \pm 49$ & $67 \pm 32$ & $<0.0001$ \\
\hline Elevated ALT and/or AST & $73 / 393(19)$ & $31 / 195(16)$ & $42 / 198(21)$ & 0.18 & $14 / 91(15)$ & $17 / 104(16)$ & $31 / 112(28)$ & $11 / 86(13)$ & 0.03 \\
\hline Elevated GGT and/or ALP & $189 / 397(48)$ & $102 / 195(52)$ & $87 / 202(43)$ & 0.07 & $55 / 93(59)$ & $47 / 102(46)$ & $50 / 120(42)$ & $37 / 82(45)$ & 0.07 \\
\hline Total bilirubin, $\mu \mathrm{mol} / 1$ & $15.8 \pm 11.9$ & $17 \pm 13$ & $15 \pm 11$ & 0.07 & $19.1 \pm 14.2$ & $15.1 \pm 11.4$ & $13.3 \pm 10.4$ & $16.6 \pm 11.2$ & 0.006 \\
\hline Prothrombin time & $74 \pm 20$ & $67 \pm 21$ & $80 \pm 16$ & $<0.0001$ & $62 \pm 22$ & $71 \pm 19$ & $78 \pm 16$ & $82 \pm 16$ & $<0.0001$ \\
\hline LV ejection fraction & $58 \pm 9$ & $57 \pm 8$ & $59 \pm 9$ & 0.03 & $55 \pm 9$ & $58 \pm 8$ & $59 \pm 10$ & $59 \pm 8$ & 0.02 \\
\hline $\mathrm{RV}$ basal diameter, $\mathrm{mm}$ & $48 \pm 11$ & $52 \pm 11$ & $44 \pm 9$ & $<0.0001$ & $52 \pm 7$ & $51 \pm 12$ & $42 \pm 9$ & $49 \pm 8$ & $<0.0001$ \\
\hline Moderate/severe RV dilatation & $245 / 450(54)$ & $148 / 222(67)$ & 97/228 (43) & $<0.0001$ & $62 / 99(63)$ & $86 / 123(70)$ & $48 / 135(36)$ & $49 / 93(53)$ & $<0.0001$ \\
\hline TAPSE, $\mathrm{mm}$ & $20 \pm 7$ & $18 \pm 5$ & $22 \pm 7$ & $<0.0001$ & $16 \pm 4$ & $19 \pm 6$ & $23 \pm 8$ & $22 \pm 7$ & $<0.0001$ \\
\hline Peak systolic annular velocity $\mathrm{S}^{\prime}, \mathrm{cm} / \mathrm{s}$ & $11.9 \pm 4.1$ & $10.7 \pm 3.1$ & $13.5 \pm 4.6$ & $<0.0001$ & $9.5 \pm 2.1$ & $11.6 \pm 3.5$ & $13.8 \pm 4.9$ & $13.2 \pm 4.1$ & $<0.0001$ \\
\hline Moderate/severe RV dysfunction & $76 / 446(17)$ & $50 / 221(23)$ & $26 / 225$ & 0.002 & $31 / 98(32)$ & $19 / 123(15)$ & $14 / 134(10)$ & $12 / 91$ (13) & 0.0002 \\
\hline $\begin{array}{l}\text { Tricuspid annulus diameter in apical } \\
\text { 4-chamber view, } \mathrm{mm}\end{array}$ & $44 \pm 9$ & $47 \pm 7$ & $41 \pm 9$ & $<0.0001$ & $46 \pm 7$ & $47 \pm 7$ & $38 \pm 9$ & $44 \pm 9$ & $<0.0001$ \\
\hline $\begin{array}{l}\text { Systolic pulmonary artery pressure, } \\
\mathrm{mmHg}\end{array}$ & $40 \pm 11$ & $43 \pm 11$ & $37 \pm 10$ & $<0.0001$ & $43 \pm 10$ & $43 \pm 12$ & $36 \pm 9.1$ & $39 \pm 11$ & $<0.0001$ \\
\hline
\end{tabular}




\section{Dreyfus et. al}

\begin{tabular}{|c|c|}
\hline Logistic EuroSCORE & $5.2[3.0-9.2]$ \\
\hline EuroSCORE II & $2.7[1.4-5.0]$ \\
\hline STS Predicted Risk of Mortality & $3.0[1.6-5.5]$ \\
\hline Charlson comorbidity index & $3[1-4]$ \\
\hline Charlson comorbidity index $\geq 2$ & $324(70)$ \\
\hline
\end{tabular}

Charlson comorbidity index $\geq 2$

\section{Isolated tricuspid valve surgery}

\begin{tabular}{c|c|c|c|c|c|c|c}
$5.2[3.3-9.7]$ & $5.2[2.6-8.8]$ & 0.78 & $7.0[4.8-12.3]$ & $4.3[2.7-7.6]$ & $6.0[3.6-11.3]$ & $3.3[1.5-6.0]$ & $<0.0001$ \\
$3.4[1.9-6]$ & $2.0[1.2-4.7]$ & 0.03 & $5.0[3.6-7.5]$ & $2.1[1.3-4.3]$ & $2.1[1.4-5.0]$ & $1.9[0.9-3.4]$ & $<0.0001$ \\
$3.6[2.2-6.1]$ & $2.3[1.1-4.8]$ & 0.05 & $4.9[3.0-7.3]$ & $3.0[1.6-4.9]$ & $2.3[1.0-5.1]$ & $2.3[1.3-4.3]$ & 0.0008 \\
$4[2-5]$ & $2[0-4]$ & $<0.0001$ & $4[2-4]$ & $3[2-5]$ & $1[0-3]$ & $3[1-5]$ & $<0.0001$ \\
$196(86)$ & $128(54)$ & $<0.0001$ & $86(85)$ & $110(86)$ & $63(44)$ & $65(68)$ & $<0.0001$
\end{tabular}


TABLE 2: In-hospital outcome overall and according to the etiology of the tricuspid regurgitation.

\begin{tabular}{|c|c|c|c|c|c|c|c|c|c|}
\hline Characteristics & $\begin{array}{l}\text { Overall } \\
(\mathrm{N}=466)\end{array}$ & $\begin{array}{l}\text { Functional } \\
(\mathrm{N}=229)\end{array}$ & $\begin{array}{l}\text { Organic } \\
(\mathrm{N}=\mathbf{2 3 7})\end{array}$ & P-value & $\begin{array}{c}\text { Functional - } \\
\text { Prior left-sided } \\
\text { heart valve } \\
\text { surgery } \\
(\mathrm{N}=101)\end{array}$ & $\begin{array}{c}\text { Functional - } \\
\text { Isolated } \\
(\mathbf{N}=128)\end{array}$ & $\begin{array}{c}\text { Organic - } \\
\text { Infective } \\
\text { endocarditis } \\
(\mathbf{N}=142)\end{array}$ & $\begin{array}{c}\text { Organic - } \\
\text { Other } \\
(\mathbf{N}=95)\end{array}$ & P-value \\
\hline Urgent surgery & $102(22)$ & $14(6)$ & $88(37)$ & $<0.0001$ & $5(5)$ & $9(7)$ & $83(58)$ & $5(5)$ & $<0.0001$ \\
\hline TV replacement & $273(57)$ & $135(59)$ & $138(58)$ & 0.87 & $76(75)$ & $59(46)$ & $78(55)$ & $60(63)$ & $<0.0001$ \\
\hline In-hospital death & $48(10)$ & $33(14)$ & $15(6)$ & 0.004 & $16(16)$ & $17(13)$ & $7(5)$ & $8(8)$ & 0.02 \\
\hline Major post-operative complications & $145(31)$ & $94(41)$ & $51(22)$ & $<0.0001$ & $48(48)$ & $46(36)$ & $29(20)$ & $22(23)$ & $<0.0001$ \\
\hline Shock & $107(23)$ & $73(32)$ & $34(14)$ & $<0.0001$ & $39(39)$ & $34(27)$ & $21(15)$ & $13(14)$ & 0.0004 \\
\hline Cardiogenic shock & $87(19)$ & $63(28)$ & $24(10)$ & $<0.0001$ & $32(32)$ & $31(24)$ & $12(8)$ & $12(13)$ & 0.0001 \\
\hline Tamponade & $36(8)$ & $26(11)$ & $10(4)$ & 0.004 & $13(13)$ & $13(10)$ & $5(4)$ & $5(5)$ & 0.03 \\
\hline Acute renal failure & $123(26)$ & $74(32)$ & $49(21)$ & 0.004 & $34(34)$ & $40(31)$ & $32(23)$ & $17(18)$ & 0.01 \\
\hline Acute renal failure requiring dialysis & 49 (11) & $32(14)$ & $17(7)$ & 0.02 & $17(17)$ & $15(12)$ & $11(8)$ & $6(6)$ & 0.02 \\
\hline Prolonged mechanical ventilation & $40(9)$ & $24(10)$ & $16(7)$ & 0.15 & $14(14)$ & $10(8)$ & $11(8)$ & $5(5)$ & 0.13 \\
\hline $\begin{array}{l}\text { New permanent pacemaker } \\
\text { implantation }\end{array}$ & $84(18)$ & $37(16)$ & $47(20)$ & 0.30 & $16(16)$ & $21(16)$ & $29(20)$ & $18(19)$ & 0.43 \\
\hline $\begin{array}{l}\text { Length of stay in intensive care unit, } \\
\text { days }\end{array}$ & $4[2-8]$ & $4[2-9]$ & $3[2-7]$ & 0.04 & $5[3-11]$ & $4[2-7]$ & $3[2-7]$ & $4[2-7]$ & 0.002 \\
\hline Length of stay in hospital, days & 18 [12-29] & 17 [12-29] & 18 [12-29] & 0.35 & $22[15-35]$ & $15[10-25]$ & $21[14-37]$ & 15 [11-23] & $<0.0001$ \\
\hline $\begin{array}{l}\text { Tricuspid regurgitation } \leq 2 \text { at } \\
\text { discharge }\end{array}$ & $408(98)$ & $192(98)$ & $216(97)$ & 0.66 & $83(98)$ & $109(98)$ & $130(92)$ & $86(99)$ & 0.58 \\
\hline $\begin{array}{l}\text { Systolic pulmonary artery pressure at } \\
\text { discharge, } \mathrm{mmHg}\end{array}$ & $36 \pm 11$ & $40 \pm 12$ & $31 \pm 8$ & $<0.0001$ & $40 \pm 11$ & $40 \pm 13$ & $29 \pm 8$ & $33 \pm 9$ & $<0.0001$ \\
\hline
\end{tabular}

Values are number of patients (percentage), mean \pm standard deviation or median (inter-quartiles)

Major post-operative complications were defined as death, shock, tamponade, acute renal failure requiring dialysis or prolonged mechanical ventilation (> 72 hours). 
TABLE 3: Univariate logistic regression for predictors of in-hospital death in adult patients undergoing an isolated tricuspid valve surgery and odd-ratios [95\% confidence interval] for the variables entered in the final model.

\begin{tabular}{|c|c|c|c|c|c|}
\hline Characteristic & $\begin{array}{c}\text { In-hospital death } \\
(\mathrm{N}=48)\end{array}$ & $\begin{array}{l}\text { Discharged alive } \\
\qquad(N=418)\end{array}$ & P-value & Odd-ratios $[95 \% \mathrm{CI}]$ & P-value \\
\hline Age, years & $68 \pm 12$ & $59 \pm 16$ & $<0.0001$ & $1.01[0.97-1.04]$ & 0.63 \\
\hline Female gender & $24(50)$ & $205(49)$ & 0.90 & & \\
\hline Body mass index, $\mathrm{kg} / \mathrm{m}^{2}$ & $26 \pm 6$ & $25 \pm 5$ & 0.61 & & \\
\hline Hypertension & $24(50)$ & $166(40)$ & 0.17 & & \\
\hline Diabetes mellitus & $6(13)$ & $56(13)$ & 0.86 & & \\
\hline Chronic lung disease & $8(17)$ & $43(10)$ & 0.18 & & \\
\hline Peripheral vascular disease & $2(4)$ & $14(3)$ & 0.77 & & \\
\hline Prior stroke & $3(6)$ & $38(9)$ & 0.51 & & \\
\hline Prior left-sided heart valve surgery & $16(33)$ & $95(23)$ & 0.10 & & \\
\hline Coronary artery disease & $9(19)$ & $50(12)$ & 0.18 & & \\
\hline Chronic kidney disease & $20(42)$ & $134(32)$ & 0.18 & & \\
\hline Chronic liver disease & $12(25)$ & $42(10)$ & 0.002 & & \\
\hline Liver cirrhosis & $3(6)$ & $8(2)$ & 0.008 & & \\
\hline Prior pacemaker & $16(33)$ & $88(21)$ & 0.05 & & \\
\hline Hospitalization for congestive heart failure ( $<1$ year) & $25(52)$ & $128(33)$ & 0.009 & & \\
\hline Systolic blood pressure, $\mathrm{mmHg}$ & $122 \pm 17$ & $125 \pm 20$ & 0.49 & & \\
\hline Diastolic blood pressure, $\mathrm{mmHg}$ & $70 \pm 14$ & $73 \pm 13$ & 0.20 & & \\
\hline NYHA functional class III-IV & $33(69)$ & $184(44)$ & 0.001 & $2.7[1.2-6.1]$ & 0.01 \\
\hline Right-sided heart failure signs & $41(85)$ & $223(53)$ & $<0.0001$ & $2.4[0.9-6.5]$ & 0.06 \\
\hline Ascites & $10(21)$ & $29(7)$ & 0.001 & & \\
\hline Loop diuretics & $41 / 47(87)$ & $260 / 404(64)$ & 0.002 & & \\
\hline Daily dose of loop diuretics, $\mathrm{mg}$ & $80[40-250]$ & $40[0-80]$ & $<0.0001$ & & \\
\hline Atrial fibrillation & $27(56)$ & $154(37)$ & 0.009 & $1.5[0.6-3.3]$ & 0.37 \\
\hline Hemoglobin, g/dl & $11.9 \pm 1.8$ & $12.3 \pm 2.3$ & 0.21 & & \\
\hline Glomerular filtration rate, $\mathrm{ml} / \mathrm{min}$ & $58 \pm 30$ & $73 \pm 40$ & 0.02 & $0.99[0.98-1.01]$ & 0.41 \\
\hline Elevated ALT and/or AST & $11 / 38(29)$ & $62 / 355(18)$ & 0.08 & & \\
\hline Elevated GGT and/or ALP & $25 / 38(26)$ & $164 / 359(46)$ & 0.02 & & \\
\hline Total bilirubin, $\mu \mathrm{mol} / 1$ & $27.3 \pm 24.0$ & $14.6 \pm 9.1$ & $<0.0001$ & & \\
\hline Prothrombin time & $62 \pm 19$ & $75 \pm 19$ & $<0.0001$ & $0.98[0.96-0.99]$ & 0.008 \\
\hline Left ventricular ejection fraction & $54 \pm 9$ & $58 \pm 9$ & 0.005 & & \\
\hline $\mathrm{RV}$ basal diameter, $\mathrm{mm}$ & $54 \pm 8$ & $47 \pm 12$ & 0.001 & & \\
\hline Moderate/severe RV dilatation & $33(69)$ & $212 / 402(53)$ & 0.04 & $1.38[0.65-2.94]$ & 0.40 \\
\hline TAPSE, $\mathrm{mm}$ & $17 \pm 6$ & $20 \pm 7$ & 0.01 & & \\
\hline Peak systolic annular velocity $\mathrm{S}^{\prime}, \mathrm{cm} / \mathrm{s}$ & $10.7 \pm 3.3$ & $12.1 \pm 4.1$ & 0.07 & & \\
\hline Moderate/severe RV dysfunction & $16(33)$ & $60 / 398(15)$ & 0.002 & $2.6[1.2-5.8]$ & 0.02 \\
\hline Tricuspid annulus diameter in apical 4-chamber view & $46 \pm 8$ & $44 \pm 9$ & 0.29 & & \\
\hline Systolic pulmonary artery pressure, $\mathrm{mmHg}$ & $45 \pm 10$ & $40 \pm 11$ & 0.01 & & \\
\hline Functional etiology of the tricuspid regurgitation & $33(69)$ & $196(47)$ & 0.004 & $0.7[0.3-1.8]$ & 0.88 \\
\hline Logistic EuroSCORE & $7.6[4.4-15.9]$ & $5[2.8-8.6]$ & $<0.0001$ & & \\
\hline EuroSCORE II & $3.7[2.5-6.7]$ & $2.5[1.3-5]$ & 0.004 & & \\
\hline STS Predicted Risk of Mortality & $4.3[2.4-7.1]$ & $2.9[1.6-5.2]$ & 0.005 & & \\
\hline
\end{tabular}


Dreyfus et. al

Charlson comorbidity index

Charlson comorbidity index $\geq 2$

Urgent surgery

Tricuspid valve replacement

ALP: Alkaline Phosphatases, T: Alanine Aminotransferase, AST: Aspartate Aminotransferase, CI: Confidence Interval, GGT: GammaGlutamyl Transferase, LV: Left Ventricle, NYHA: New York Heart Association, RV: Right Ventricle, TAPSE: Tricuspid Annular Plane Systolic Excursion, STS: Society of Thoracic Surgery, TR: Tricuspid Regurgitation, TV: Tricuspid Valve

\section{Isolated tricuspid valve surgery}

$\begin{array}{c:c}4[3-6] & 3[1-4] \\ 43(90) & 280(67) \\ 9(19) & 93(22) \\ 33(69) & 240(57)\end{array}$


Figure 1.

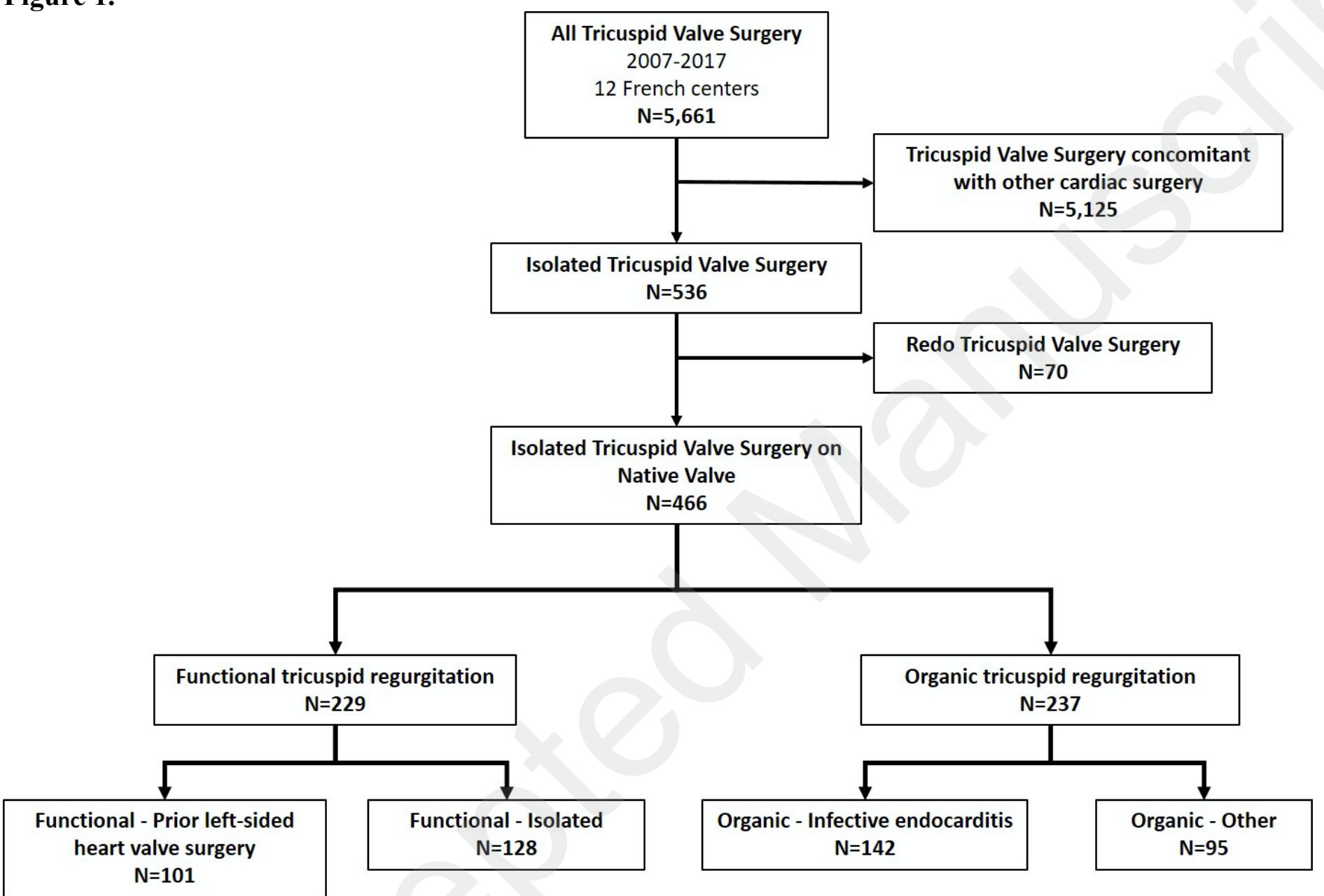


Dreyfus et. al

Figure 2.

A

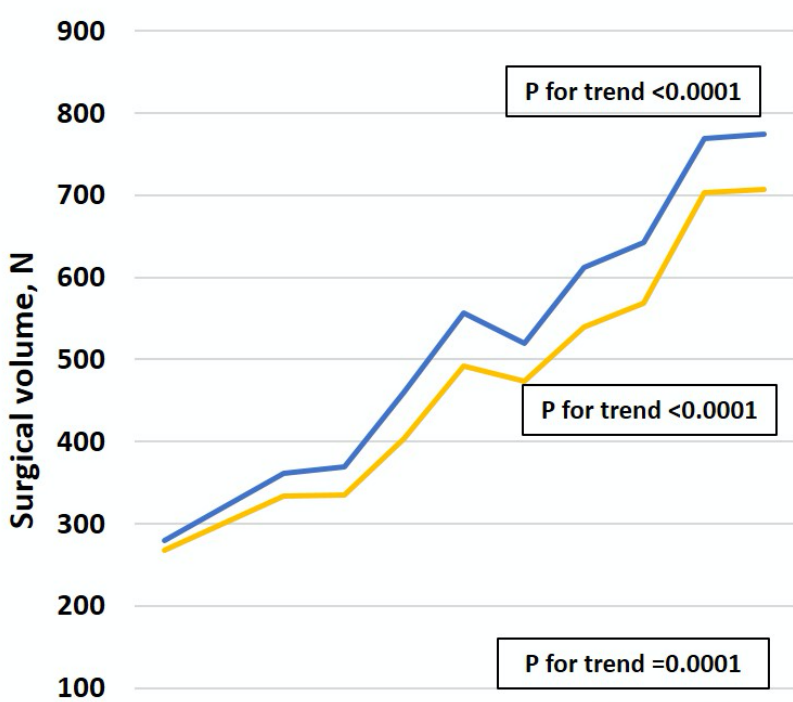

0

20072008200920102011201220132014201520162017 Year

\section{-All TV surgery \\ - Isolated TV surgery on native valve \\ - Combined TV surgery}

B

900

800

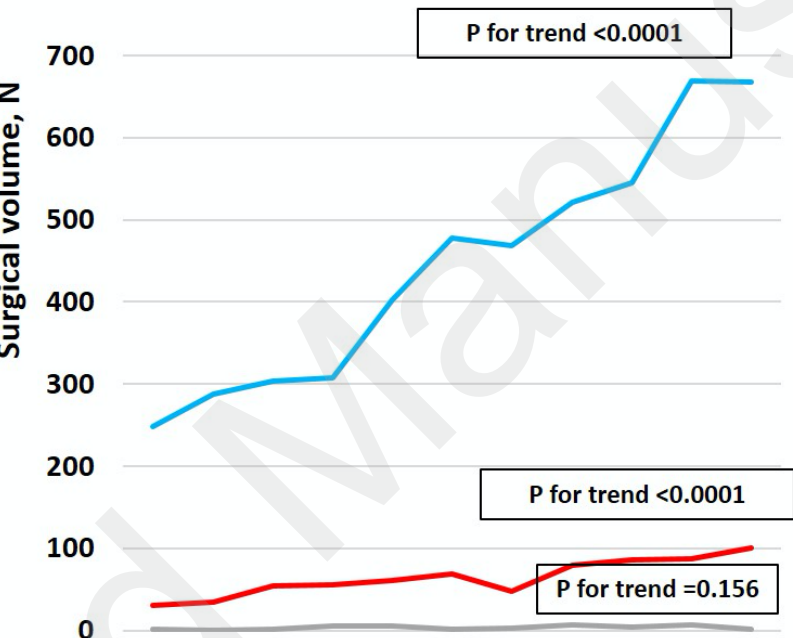

20072008200920102011201220132014201520162017 Year

-TV repair

-TV replacement - bioprosthetic

- TV replacement - mechanical 
Figure 3.

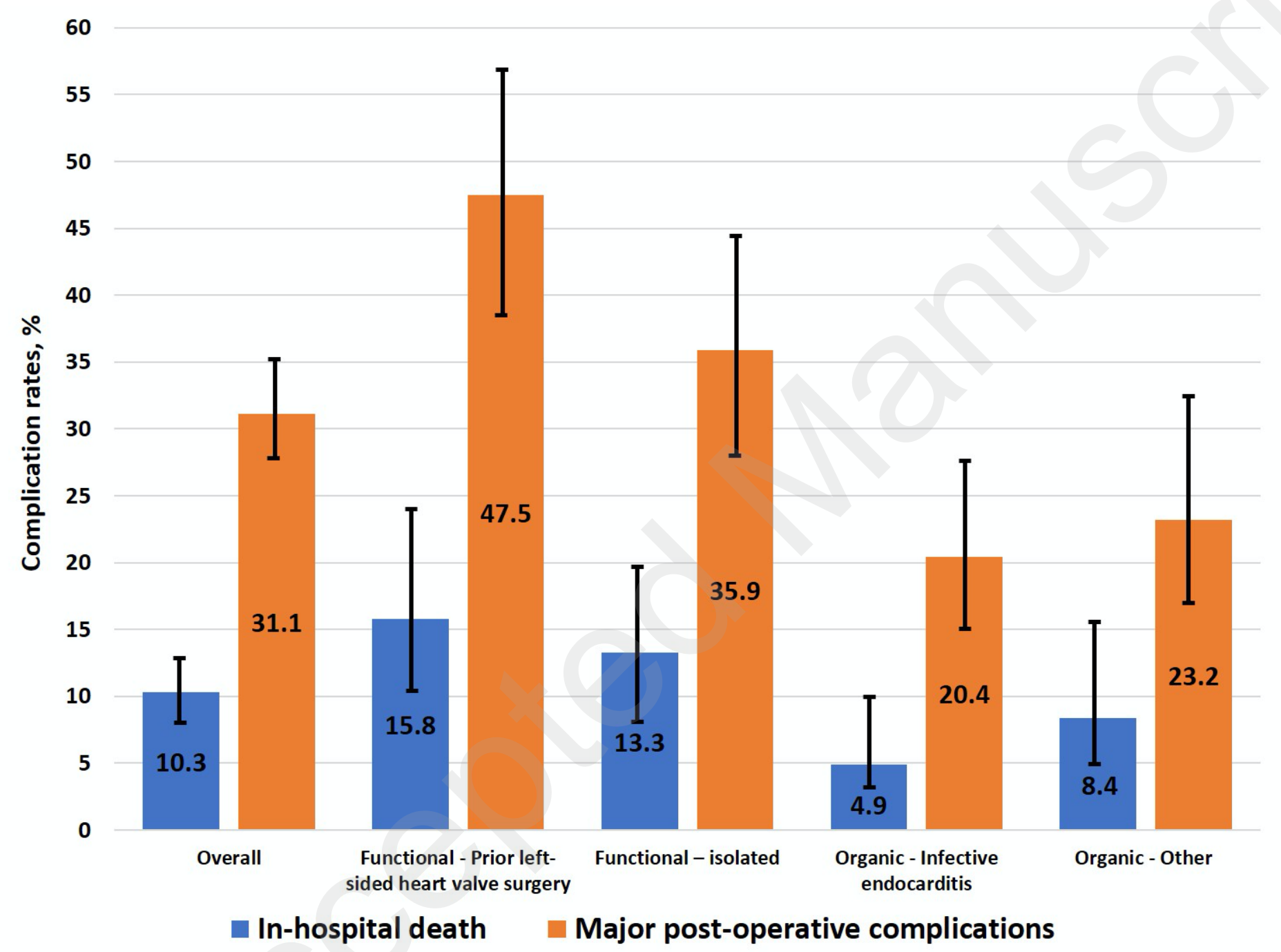


Dreyfus et. al

Figure 4.

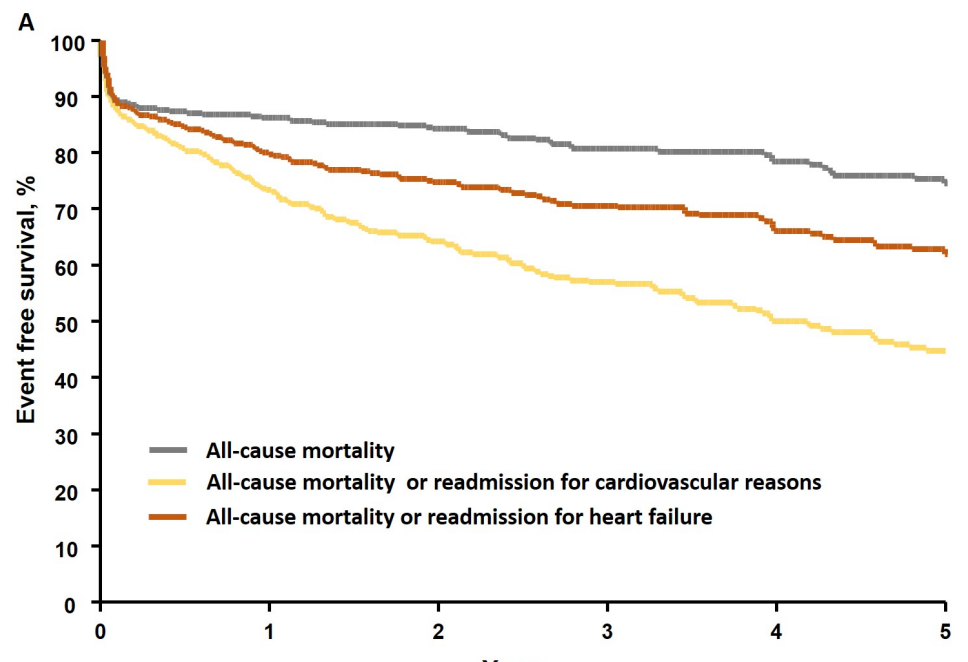

Number at risk

$\begin{array}{llllll}-466 & 301 & 242 & 188 & 141 & 100 \\ -466 & 261 & 198 & 150 & 106 & 77 \\ -466 & 280 & 219 & 173 & 127 & 91\end{array}$

\section{Isolated tricuspid valve surgery}

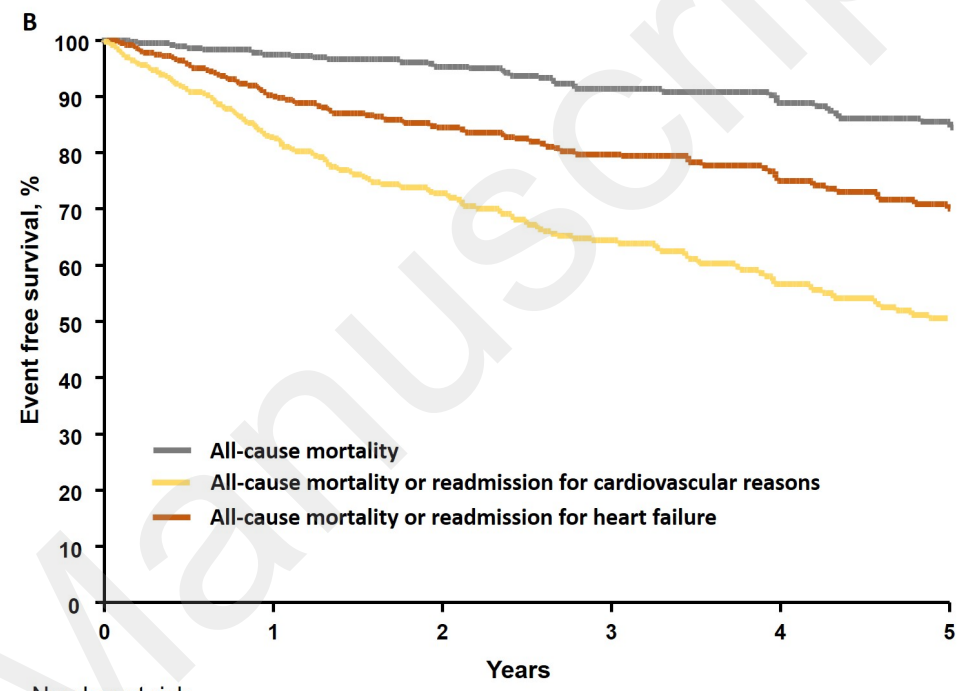

Number at risk

$\begin{array}{rlllll}-371 & 301 & 242 & 188 & 141 & 100 \\ -371 & 261 & 198 & 150 & 106 & 77 \\ -371 & 280 & 219 & 173 & 127 & 91\end{array}$


Figure 5.
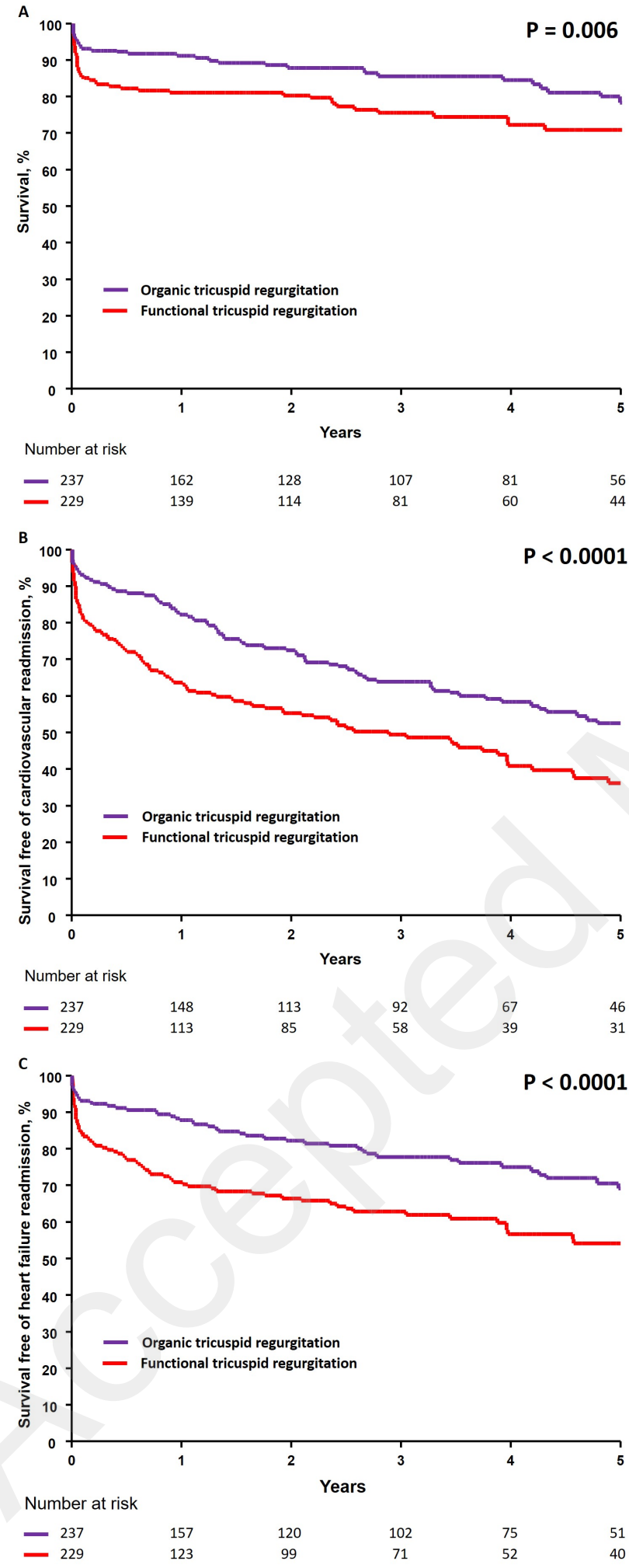
Take-home figure. Isolated tricuspid valve surgery is associated with high mortality and morbidity, both in-hospital and during follow-up, predicted by the severity of the pre-operative clinical, biological and echocardiographic presentation but not by tricuspid regurgitation mechanism.

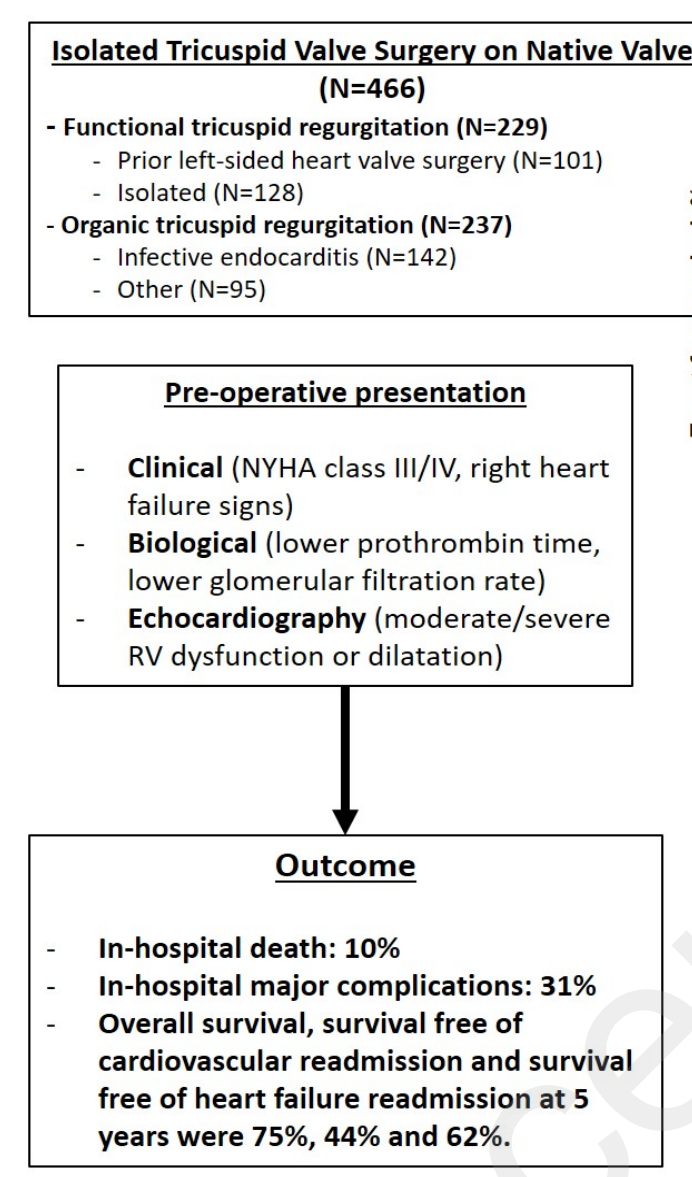

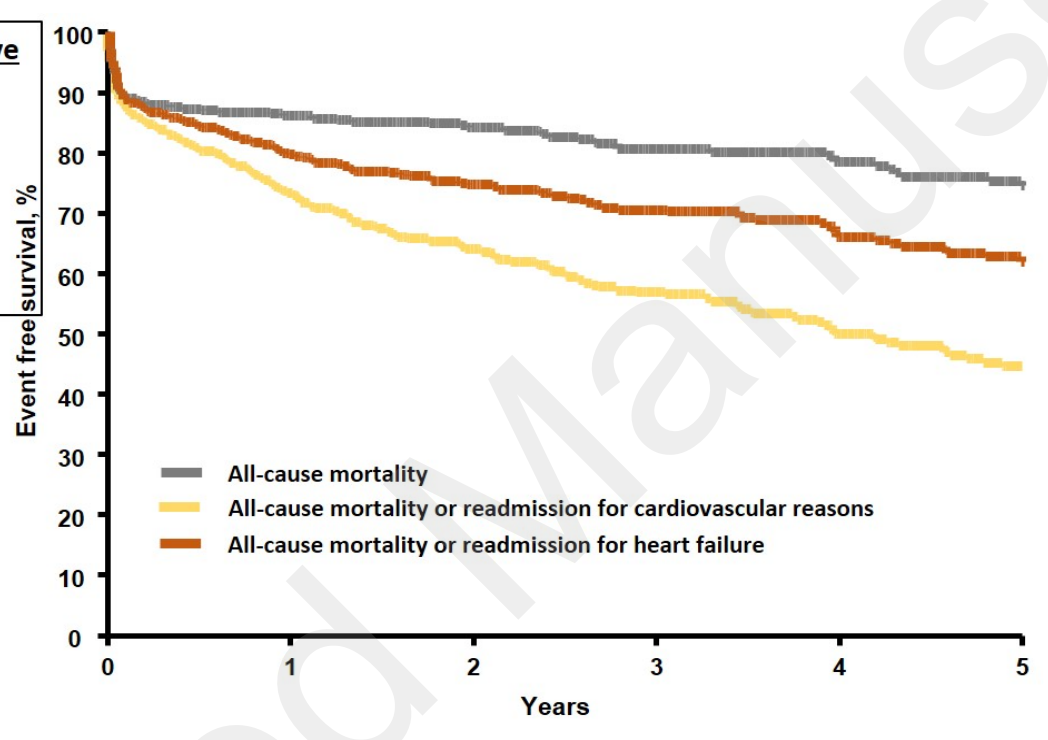

Isolated tricuspid valve surgery is associated with high mortality and morbidity, both in-hospital and during follow-up, predicted by the severity of the pre-operative clinical, biological and echocardiographic presentation but not by etiology or the mechanism tricuspid regurgitation mechanism 
Dreyfus et. al

Isolated tricuspid valve surgery

Supplementary table. Univariate logistic regression for predictors of in-hospital death in adult patients undergoing an isolated tricuspid valve surgery according to the mechanism and etiology of the tricuspid regurgitation.

\begin{tabular}{|c|c|c|c|c|c|c|c|c|c|c|c|c|c|c|c|c|c|c|}
\hline \multirow[b]{2}{*}{ Characteristic } & \multicolumn{3}{|c|}{$\begin{array}{c}\text { Functional } \\
(\mathrm{N}=229)\end{array}$} & \multicolumn{3}{|c|}{$\begin{array}{l}\text { Organic } \\
(\mathrm{N}=237)\end{array}$} & \multicolumn{3}{|c|}{$\begin{array}{c}\text { Functional - Prior left-sided } \\
\text { heart valve surgery } \\
(\mathrm{N}=101)\end{array}$} & \multicolumn{3}{|c|}{$\begin{array}{c}\text { Functional - Isolated } \\
(\mathbf{N}=128)\end{array}$} & \multicolumn{3}{|c|}{$\begin{array}{c}\text { Organic - Infective endocarditis } \\
(\mathrm{N}=\mathbf{1 4 2})\end{array}$} & \multicolumn{3}{|c|}{$\begin{array}{c}\text { Organic - Other } \\
(\mathrm{N}=95)\end{array}$} \\
\hline & $\begin{array}{c}\text { In-hospital } \\
\text { death } \\
(\mathrm{N}=33)\end{array}$ & $\begin{array}{c}\begin{array}{c}\text { Discharged } \\
\text { alive } \\
(\mathrm{N}=196)\end{array} \\
\end{array}$ & P-value & $\begin{array}{c}\text { In-hospital } \\
\text { death } \\
(\mathbf{N}=15)\end{array}$ & $\begin{array}{c}\begin{array}{c}\text { Discharged } \\
\text { alive } \\
(\mathrm{N}=222)\end{array} \\
\end{array}$ & P-value & $\begin{array}{c}\text { In-hospital } \\
\text { death } \\
(\mathrm{N}=16) \\
\end{array}$ & \begin{tabular}{|c|} 
Discharged \\
alive \\
$(\mathrm{N}=85)$ \\
\end{tabular} & P-value & $\begin{array}{c}\begin{array}{c}\text { In-hospital } \\
\text { death } \\
(\mathrm{N}=17)\end{array} \\
\end{array}$ & 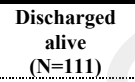 & P-value & $\begin{array}{l}\text { In-hospital } \\
\text { death } \\
(\mathrm{N}=7) \\
\end{array}$ & 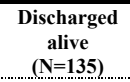 & P-value & $\begin{array}{l}\text { In-hospital } \\
\text { death } \\
(\mathrm{N}=\mathbf{8}) \\
\end{array}$ & $\begin{array}{c}\text { Discharged } \\
\text { alive } \\
(\mathrm{N}=87) \\
\end{array}$ & P-value \\
\hline Age, years & $70 \pm 10$ & $66 \pm 12$ & 0.04 & $63 \pm 14$ & $53 \pm 17$ & 0.03 & $66 \pm 11$ & $66 \pm 11$ & 0.98 & $74 \pm 8$ & $65 \pm 12$ & 0.01 & $62 \pm 18$ & $49 \pm 17$ & 0.05 & $64 \pm 11$ & $60 \pm 16$ & 0.44 \\
\hline Female gender & $19(58)$ & $118(60)$ & 0.78 & $5(33)$ & $135(61)$ & 0.65 & $12(75)$ & $52(61)$ & 0.01 & $7(41)$ & $66(59)$ & 0.16 & $0(0)$ & $92(68)$ & 0.07 & $5(63)$ & $44(51)$ & 0.52 \\
\hline Body mass index, $\mathrm{kg} / \mathrm{m}^{2}$ & $26 \pm 6$ & $27 \pm 5$ & 0.69 & $25 \pm 5$ & $24 \pm 5$ & 0.65 & $25 \pm 6$ & $26 \pm 5$ & 0.37 & $27 \pm 6$ & $27 \pm 6$ & 0.73 & $24 \pm 8$ & $24 \pm 4$ & 0.91 & $25 \pm 3$ & $25 \pm 5$ & 0.79 \\
\hline Hypertension & $17(52)$ & $103(53)$ & 0.91 & $7(47)$ & $63(28)$ & 0.13 & $8(50)$ & $39(46)$ & 0.76 & $9(53)$ & $64(58)$ & 0.71 & $4(57)$ & $27(20)$ & 0.02 & $3(38)$ & $36(41)$ & 0.83 \\
\hline Diabetes mellitus & $4(12)$ & $36(18)$ & 0.38 & $2(13)$ & $20(9)$ & 0.58 & $2(13)$ & $17(20)$ & 0.48 & $2(12)$ & 19 (17) & 0.58 & $2(29)$ & $11(8)$ & 0.07 & $0(0)$ & $9(10)$ & 0.34 \\
\hline Chronic lung disease & $6(18)$ & $24(12)$ & 0.35 & $2(13)$ & $19(9)$ & 0.53 & $3(19)$ & $11(13)$ & 0.54 & $3(18)$ & $13(12)$ & 0.49 & $2(29)$ & $11(8)$ & 0.07 & $0(0)$ & $8(9)$ & 0.37 \\
\hline Peripheral vascular disease & $0(0)$ & $5(3)$ & 0.35 & $2(13)$ & $9(4)$ & 0.10 & $0(0)$ & $1(1)$ & 0.66 & $0(0)$ & $4(4)$ & 0.43 & $2(29)$ & $6(4)$ & 0.007 & $0(0)$ & $3(3)$ & 0.59 \\
\hline Prior stroke & $2(1)$ & $22(11)$ & 0.37 & $1(7)$ & $16(7)$ & 0.9 & $1(6)$ & $14(16)$ & 0.29 & $1(6)$ & $8(7)$ & 0.84 & $1(14)$ & $8(6)$ & 0.38 & $0(0)$ & $8(9)$ & 0.37 \\
\hline Coronary artery disease & $5(15)$ & $30(15)$ & 0.98 & $4(27)$ & $20(9)$ & 0.03 & $4(25)$ & $16(19)$ & 0.57 & $1(6)$ & $14(13)$ & 0.42 & $2(29)$ & $10(7)$ & 0.05 & $2(25)$ & $10(11)$ & 0.27 \\
\hline Chronic kidney disease & $14(42)$ & $86(44)$ & 0.88 & $6(40)$ & $48(22)$ & 0.10 & $7(44)$ & $45(53)$ & 0.50 & $7(41)$ & $41(37)$ & 0.74 & $3(43)$ & $25(19)$ & 0.11 & $3(38)$ & $23(26)$ & 0.50 \\
\hline Chronic liver disease & $8(24)$ & $23(12)$ & 0.05 & $4(27)$ & $19(9)$ & 0.02 & $4(25)$ & $12(14)$ & 0.27 & $4(24)$ & $11(10)$ & 0.10 & $0(0)$ & $10(7)$ & 0.46 & $4(50)$ & $9(10)$ & 0.002 \\
\hline Liver cirrhosis & $3(9)$ & $4(2)$ & 0.03 & $0(0)$ & $4(2)$ & 0.6 & $1(6)$ & $4(5)$ & 0.79 & $2(12)$ & $0(0)$ & 0.0003 & $0(0)$ & $0(0)$ & - & $0(0)$ & $4(5)$ & 0.54 \\
\hline Prior pacemaker & $13(39)$ & $41(21)$ & 0.02 & $3(20)$ & $47(21)$ & 0.91 & $5(31)$ & $21(25)$ & 0.58 & $8(47)$ & $20(18)$ & 0.007 & $3(43)$ & $26(19)$ & 0.13 & $0(0)$ & $21(24)$ & 0.12 \\
\hline $\begin{array}{l}\text { Hospitalization for congestive heart } \\
\text { failure }<<1 \text { year })\end{array}$ & $22(67)$ & $99(51)$ & 0.09 & $3(20)$ & $39(18)$ & 0.81 & $9(56)$ & $48(56)$ & 0.99 & $13(76)$ & $51(46)$ & 0.02 & $1(14)$ & $15(11)$ & 0.80 & $2(25)$ & $24(28)$ & 0.88 \\
\hline Systolic blood pressure, $\mathrm{mmHg}$ & $124 \pm 16$ & $126 \pm 20$ & 0.55 & $120 \pm 18$ & $124 \pm 20$ & 0.54 & $126 \pm 18$ & $123 \pm 20$ & 0.57 & $121 \pm 15$ & $128 \pm 19$ & 0.19 & $114 \pm 17$ & $122 \pm 19$ & 0.32 & $129 \pm 17$ & $127 \pm 21$ & 0.89 \\
\hline Diastolic blood pressure, $\mathrm{mmHg}$ & $71 \pm 13$ & $72 \pm 13$ & 0.69 & $67 \pm 15$ & $74 \pm 14$ & 0.14 & $74 \pm 16$ & $69 \pm 12$ & 0.15 & $68 \pm 10$ & $75 \pm 13$ & 0.07 & $62 \pm 11$ & $74 \pm 14$ & 0.05 & $75 \pm 18$ & $74 \pm 14$ & 0.93 \\
\hline NYHA functional class III-IV & $23(70)$ & $113(58)$ & 0.19 & $10(67)$ & $71(32)$ & 0.006 & $11(69)$ & $51(60)$ & 0.51 & $12(71)$ & $62(56)$ & 0.25 & $3(43)$ & $38(28)$ & 0.40 & $7(88)$ & $33(38)$ & 0.007 \\
\hline Right-sided heart failure signs & $30(91)$ & $136(69)$ & 0.01 & $11(73)$ & $87(39)$ & 0.009 & $14(88)$ & $66(78)$ & 0.37 & $16(94)$ & $70(63)$ & 0.01 & $3(43)$ & $45(33)$ & 0.60 & $8(100)$ & $42(48)$ & 0.005 \\
\hline $\begin{array}{l}\text { Ascites } \\
\text { - }\end{array}$ & $7(21)$ & $22(11)$ & 0.11 & $3(20)$ & $7(3)$ & 0.002 & $3(19)$ & $12(14)$ & 0.63 & $4(24)$ & $10(9)$ & 0.07 & $0(0)$ & $1(1)$ & 0.82 & $3(38)$ & $6(7)$ & 0.005 \\
\hline Loop diuretics & $33(100)$ & $161(85)$ & 0.02 & $8(57)$ & $99(46)$ & 0.42 & $16(100)$ & 80 (94) & 0.32 & $17(100)$ & $81(78)$ & 0.03 & $3(50)$ & $46(35)$ & 0.47 & $5(63)$ & $53(62)$ & 0.99 \\
\hline Daily dose of loop diuretics, $\mathrm{mg}$ & $125[70-250]$ & $60[40-120]$ & $<0.0001$ & $20[0-65]$ & $0[0-40]$ & 0.06 & 100 [50-250] & $80[40-120]$ & 0.05 & $125[70-250]$ & $40[20-80]$ & 0.003 & $20[0-400]$ & $0[0-40]$ & 0.03 & $20[0-75]$ & $40[0-80]$ & 0.78 \\
\hline Atrial fibrillation & $25(76)$ & $117(60)$ & 0.08 & $2(13)$ & $37(17)$ & 0.74 & $13(81)$ & $53(62)$ & 0.15 & $12(71)$ & $64(58)$ & 0.31 & $2(29)$ & $15(11)$ & 0.17 & $0(0)$ & $22(25)$ & 0.10 \\
\hline Hemogl & $11.9 \pm 1.6$ & $12.6 \pm 2$ & 0.07 & $11.8 \pm 2.3$ & $12.1 \pm 2.5$ & 0.72 & $12.1 \pm 1.3$ & $12.1 \pm 2$ & 0.88 & $11.7 \pm 1.8$ & $12.9 \pm 2$ & 0.03 & $10.6 \pm 2$ & $11.2 \pm 2.5$ & 0.58 & $13 \pm 2.1$ & $13.4 \pm 9$ & 0.62 \\
\hline on rate, $\mathrm{ml} / \mathrm{min}$ & $55 \pm 24$ & $61 \pm 30$ & 0.25 & $67 \pm 41$ & $83 \pm 45$ & 0.20 & $54 \pm 25$ & $61 \pm 29$ & 0.37 & $55 \pm 24$ & $62 \pm 31$ & 0.46 & $87 \pm 44$ & $93 \pm 49$ & 0.75 & $46 \pm 28$ & $69 \pm 32$ & 0.09 \\
\hline Elevated ALT & $7(25)$ & $24(14)$ & 0.15 & $4(40)$ & $38(20)$ & 0.14 & $3(23)$ & $11(14)$ & 0.41 & $4(27)$ & $13(15)$ & 0.24 & $2(50)$ & 29 (27) & 0.31 & $2(33)$ & $9(11)$ & 0.12 \\
\hline $\begin{array}{l}\text { Elevated GGT and/or ALP } \\
\text { ele }\end{array}$ & $19(68)$ & $83(50)$ & 0.08 & $6(60)$ & $81(42)$ & 0.27 & $9(64)$ & $46(58)$ & 0.67 & $10(71)$ & $37(42)$ & 0.04 & $3(60)$ & $47(41)$ & 0.40 & $3(60)$ & $34(44)$ & 0.49 \\
\hline Total bilirubin, $\mu \mathrm{mol} / 1$ & $28 \pm 26.3$ & $15.2 \pm 8$ & 0.001 & $25.6 \pm 18.6$ & $14 \pm 9.9$ & 0.003 & $33.9 \pm 29.8$ & $16.9 \pm 8.7$ & 0.01 & $23.6 \pm 23.5$ & $13.7 \pm 7.1$ & 0.04 & $24 \pm 20.2$ & $12.9 \pm 9.8$ & 0.06 & $26.6 \pm 19.2$ & $15.7 \pm 9.9$ & 0.03 \\
\hline Prothrombin time & $57 \pm 18$ & $69 \pm 21$ & 0.009 & $72 \pm 17$ & $80 \pm 16$ & 0.07 & $57 \pm 21$ & $63 \pm 23$ & 0.38 & $58 \pm 16$ & $73 \pm 19$ & 0.006 & $64 \pm 11$ & $79 \pm 16$ & 0.03 & $79 \pm 18$ & $82 \pm 16$ & 0.62 \\
\hline Left ventricular ejection fraction & $55 \pm 8$ & $57 \pm 9$ & 0.28 & $52 \pm 12$ & $59 \pm 9$ & 0.007 & $55 \pm 6$ & $55 \pm 9$ & 0.95 & $55 \pm 9$ & $58 \pm 8$ & 0.17 & $47 \pm 14$ & $59 \pm 9$ & 0.003 & $57 \pm 7$ & $59 \pm 8$ & 0.61 \\
\hline $\mathrm{RV}$ basal diameter, $\mathrm{mm}$ & $56 \pm 8$ & $50 \pm 11$ & 0.05 & $48 \pm 7$ & $44 \pm 9$ & 0.26 & $56 \pm 6$ & $51 \pm 6$ & 0.04 & $55 \pm 9$ & $50 \pm 13$ & 0.25 & $46 \pm 1$ & $41 \pm 9$ & 0.52 & $50 \pm 9$ & $49 \pm 8$ & 0.82 \\
\hline Moderate/severe RV dilatation & $25(76)$ & $123(65)$ & 0.23 & $8(53)$ & $89(42)$ & 0.38 & $12(75)$ & $50(60)$ & 0.26 & $13(76)$ & $73(69)$ & 0.53 & $4(57)$ & $44(34)$ & 0.22 & $4(50)$ & $45(53)$ & 0.87 \\
\hline TAPSE, $\mathrm{mm}$ & $17 \pm 5$ & $18 \pm 5$ & 0.45 & $18 \pm 8$ & $23 \pm 7$ & 0.08 & $17 \pm 3$ & $16 \pm 4$ & 0.32 & $17 \pm 6$ & $19 \pm 6$ & 0.19 & $15 \pm 8$ & $23 \pm 7$ & 0.08 & $20 \pm 9$ & $23 \pm 7$ & 0.49 \\
\hline $\begin{array}{l}\text { Peak systolic annular velocity } \mathrm{S}^{\prime}, \\
\mathrm{cm} / \mathrm{s}\end{array}$ & $10.4 \pm 2.8$ & $10.8 \pm 3.2$ & 0.59 & $11.9 \pm 5$ & $13.6 \pm 4.5$ & 0.33 & $9.9 \pm 2.3$ & $9.5 \pm 2.1$ & 0.50 & $10.8 \pm 3.1$ & $11.7 \pm 3.5$ & 0.35 & $11 \pm 4$ & $13.9 \pm 5$ & 0.42 & $12.2 \pm 6$ & $13.2 \pm 3.9$ & 0.58 \\
\hline Moderate/severe RV dysfunction & $10(30)$ & $40(21)$ & 0.25 & $6(40)$ & $20(10)$ & 0.0004 & $6(38)$ & $25(30)$ & 0.58 & $4(24)$ & $15(14)$ & 0.32 & $2(29)$ & $12(9)$ & 0.11 & $4(50)$ & $8(10)$ & 0.001 \\
\hline $\begin{array}{l}\text { Tricuspid annulus diameter in apical } \\
\text { 4-chamber view }\end{array}$ & $47 \pm 6$ & $47 \pm 7$ & 0.69 & $41 \pm 10$ & $41 \pm 9$ & 0.95 & $46 \pm 7$ & $46 \pm 6$ & 0.82 & $49 \pm 5$ & $47 \pm 7$ & 0.43 & $35 \pm 6$ & $39 \pm 9$ & 0.48 & $44 \pm 10$ & $44 \pm 9$ & 0.94 \\
\hline Systolic pulmonary artery pressure, & $46 \pm 9$ & $42 \pm 11$ & 0.17 & $42 \pm 12$ & $37 \pm 10$ & 0.19 & $43 \pm 10$ & $43 \pm 10$ & 0.96 & $48 \pm 8$ & $42 \pm 12$ & 0.10 & $44 \pm 13$ & $35 \pm 9$ & 0.13 & $41 \pm 14$ & $39 \pm 11$ & 0.79 \\
\hline $\begin{array}{l}\mathrm{mmHg} \\
\text { Logistic EuroSCORE }\end{array}$ & $7.7[4.9-12.7]$ & $5[3.3-9]$ & 0.009 & $6.8[4.3 .17 .5]$ & $5[2.4-8.6]$ & 0.07 & $9[5.7-12.7]$ & $6.7[4.4-11.9]$ & 0.19 & $7.6[4.1-13.1]$ & $4[2.5-6.4]$ & 0.003 & 16.4 [6.8-24] & $5.6[3.6-10]$ & 0.06 & $4.2[1.9-11.2]$ & $3[1.5-6]$ & 0.12 \\
\hline EuroSCORE II & $3.4[2.4-6.5]$ & $3.4[1.7-6]$ & 0.64 & $4.2[2.8-8]$ & $1.9[1.2-4.5]$ & 0.29 & $5[3.6-8.5]$ & $5[3.6-7.2]$ & 0.87 & $2.4[1.9-4.2]$ & $2[1.2-4.4]$ & 0.83 & $5[4.2-9.9]$ & $2[1.4-5]$ & 0.30 & $2.9[1.5-4.6]$ & $1.8[0.9-3.3]$ & 0.30 \\
\hline STS Predicted Risk of Mortality & $4.5[2.5-6.9]$ & $3.6[2.1-5.8]$ & 0.48 & $3.6[2.2-7.9]$ & $2.3[1-4.8]$ & 0.39 & $5.4[2.8-7.8]$ & $4.8[3.1-7.1]$ & 0.56 & $4.4[1.8-5.8]$ & $2.8[1.6-4.5]$ & 0.12 & $5.1[2.5-10]$ & $2.2[1-5.1]$ & 0.46 & $3.5[1.8-6.9]$ & $2.3[1.2-4.3]$ & 0.44 \\
\hline Charlson co & $4[3-5.5]$ & $3[2-5]$ & 0.09 & $4[3-7]$ & $2[0-4]$ & 0.0005 & $3[2-5]$ & $4[2-4]$ & 0.99 & $4[3.5-6.5]$ & $3[2-5]$ & 0.0 & $4[1-6]$ & $1[0-3]$ & 0.0 & $4.5[3.3-8.5]$ & $4.5[3.3-8.5]$ & 0.02 \\
\hline Charlson comorbidity index $\geq 2$ & $30(91)$ & $166(85)$ & 0.35 & $13(87)$ & $115(52)$ & 0.009 & $14(88)$ & $72(85)$ & 0.77 & $16(94)$ & $94(85)$ & 0.3 & $5(7$ & $58(43)$ & 0.14 & $8(100)$ & $57(66)$ & 0.05 \\
\hline Urgent surgery & 1( & 13 & 0.42 & $8(53)$ & $80(36)$ & 0.18 & 0( & $5(6$ & 0.32 & $1(6$ & $8(7$ & 0.8 & $7(100)$ & $76(56)$ & 0.02 & $1(13)$ & $4(5)$ & 0.34 \\
\hline Tricuspid valve replacement & $21(64)$ & $114(58)$ & 0.55 & $12(80)$ & $126(57)$ & 0.08 & $12(75)$ & $64(75)$ & 0.98 & $9(53)$ & $50(45)$ & 0.54 & $5(71)$ & $73(54)$ & 0.37 & $7(88)$ & $53(61)$ & 0.14 \\
\hline
\end{tabular}


ALP: Alkaline Phosphatases, T: Alanine Aminotransferase, AST: Aspartate Aminotransferase, GGT: Gamma-Glutamyl Transferase, LV: Left Ventricle, NYHA: New York Heart Association, RV: Right Ventricle, TAPSE: Tricuspid Annular Plane Systolic Excursion, STS: Society of Thoracic Surgery, TR: Tricuspid Regurgitation, TV: Tricuspid Valve 
Supplementary figure 1 . Location of the 12 French participating centers.

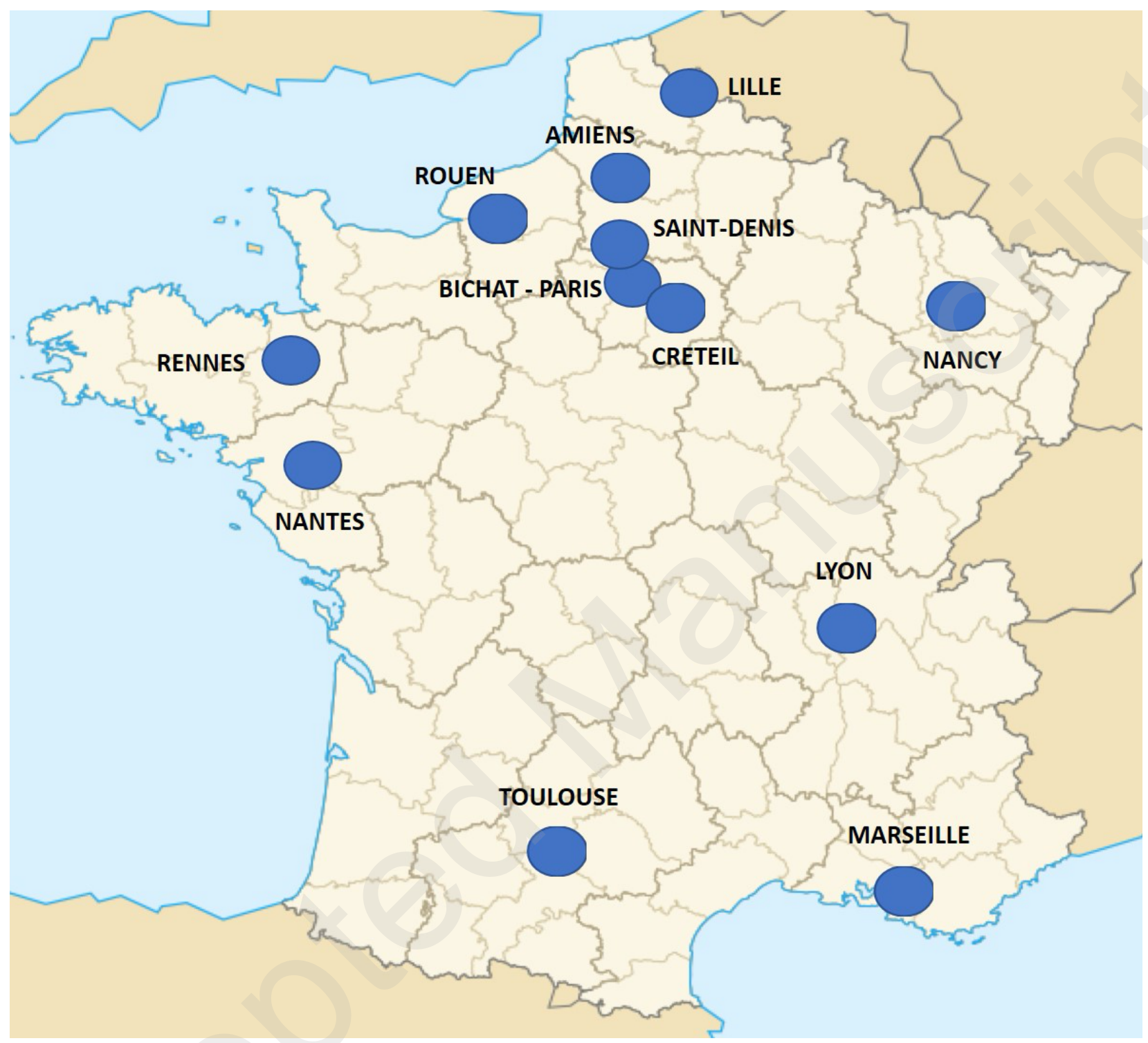


Supplementary figure 2. Type of tricuspid valve surgery.

Type of tricuspid valve surgery performed (tricuspid valve repair, bioprosthetic tricuspid valve replacement or mechanical tricuspid valve replacement) in the total population, in patients who underwent a combined tricuspid valve surgery and in patients who underwent an isolated tricuspid valve surgery.

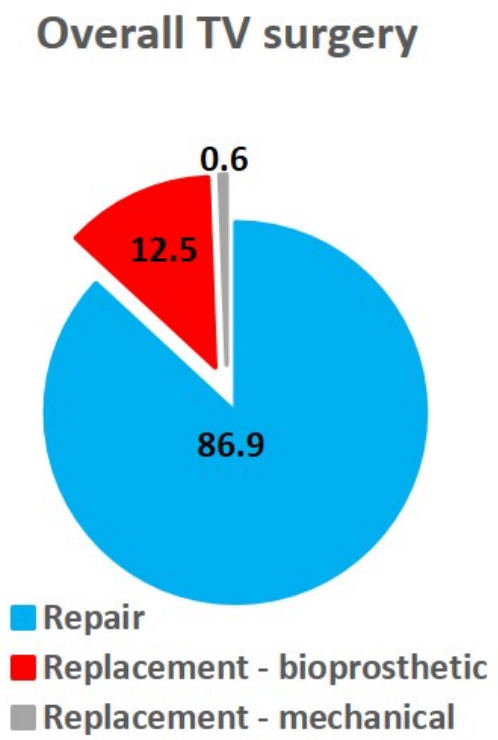

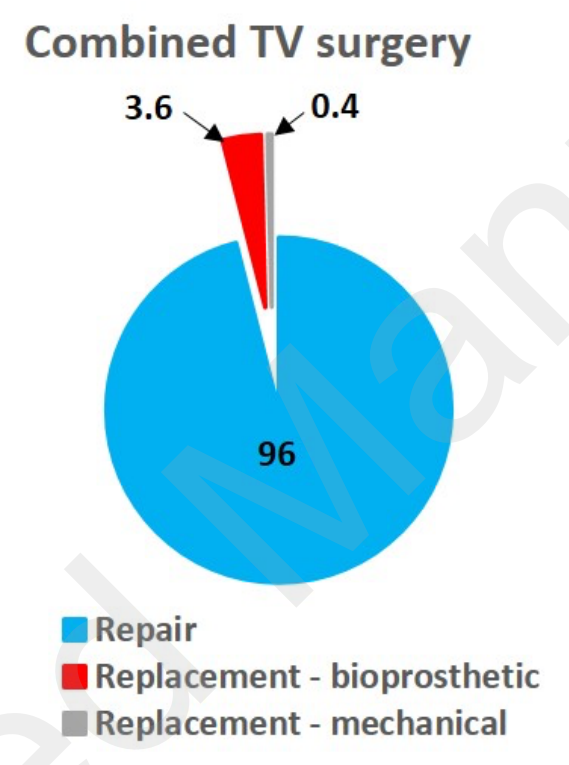

\section{Isolated TV surgery}

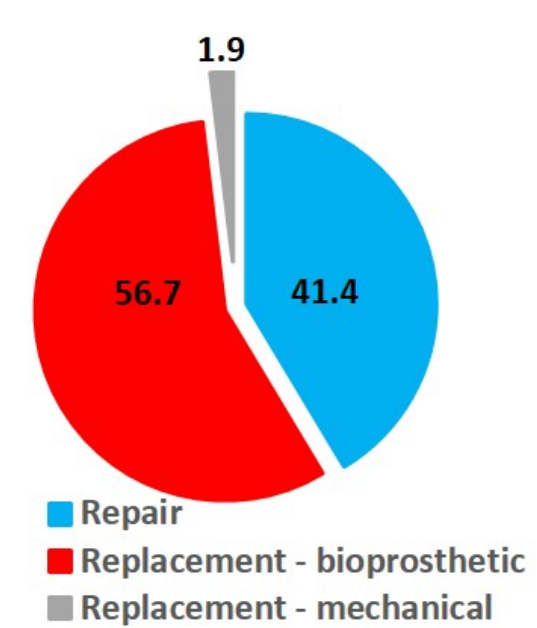


Supplementary figure 3. Events rate according to the etiology of the tricuspid regurgitation. The figure displays Kaplan-Meier curves of (A) Survival, (B) Survival free of cardiovascular readmission and (C) Survival free of heart failure readmission for functional tricuspid regurgitation after left-sided valve surgery (in red), isolated functional TR (in green), organic TR due to infective endocarditis (in blue) and organic TR due other etiologies (in orange).
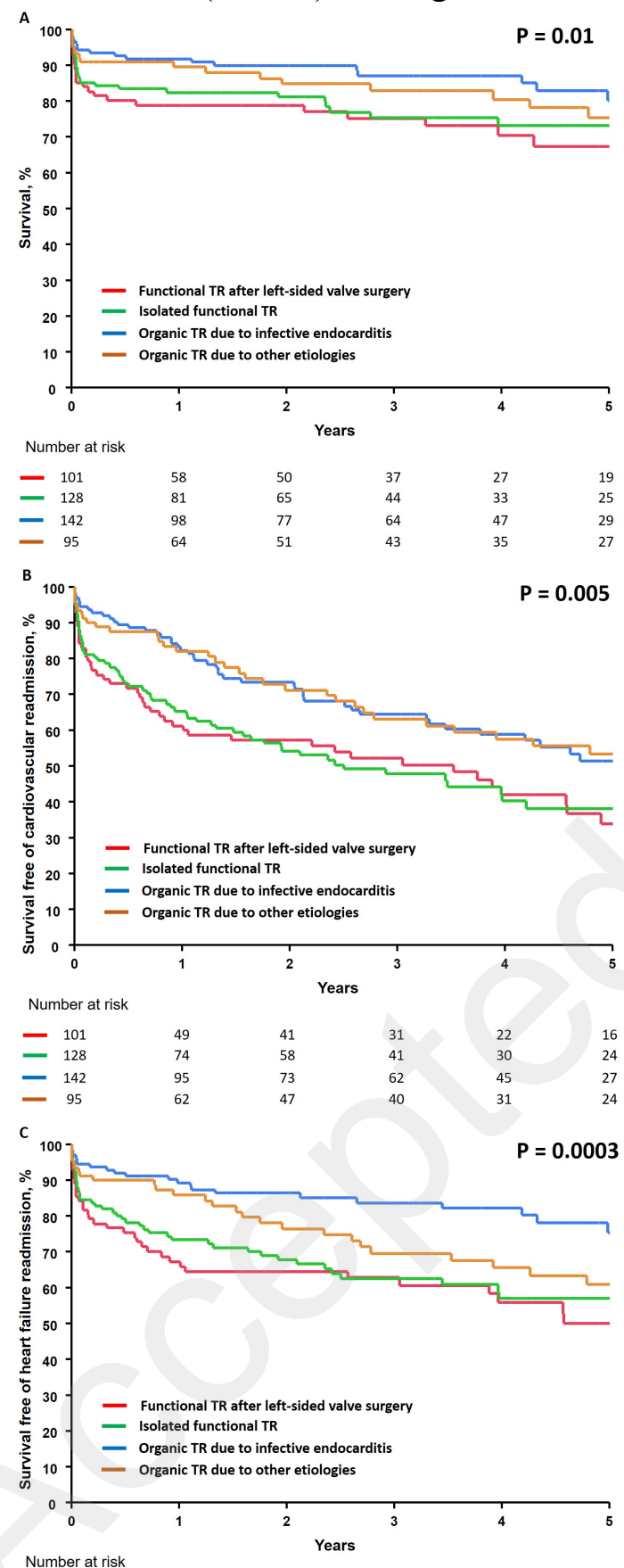

$\begin{array}{llllll}\text { Number at risk } & & & & & \\ \text { - } 101 & 49 & 41 & 31 & 22 & 17 \\ \text { - } 128 & 74 & 59 & 41 & 31 & 25 \\ \text { - } 142 & 95 & 73 & 62 & 45 & 27 \\ -95 & 62 & 47 & 40 & 30 & 24\end{array}$

